Natural Hazards and Earth System Sciences, 6, 115-131, 2006

SRef-ID: 1684-9981/nhess/2006-6-115

European Geosciences Union

(C) 2006 Author(s). This work is licensed

under a Creative Commons License.

\title{
Landslide hazard assessment in the Collazzone area, Umbria, Central Italy
}

\author{
F. Guzzetti, M. Galli, P. Reichenbach, F. Ardizzone, and M. Cardinali \\ IRPI CNR, via Madonna Alta 126, 06128 Perugia, Italy \\ Received: 2 November 2005 - Revised: 20 December 2005 - Accepted: 20 December 2005 - Published: 31 January 2006
}

\begin{abstract}
We present the results of the application of a recently proposed model to determine landslide hazard. The model predicts where landslides will occur, how frequently they will occur, and how large they will be in a given area. For the Collazzone area, in the central Italian Apennines, we prepared a multi-temporal inventory map through the interpretation of multiple sets of aerial photographs taken between 1941 and 1997 and field surveys conducted in the period between 1998 and 2004. We then partitioned the 79 square kilometres study area into 894 slope units, and obtained the probability of spatial occurrence of landslides by discriminant analysis of thematic variables, including morphology, lithology, structure and land use. For each slope unit, we computed the expected landslide recurrence by dividing the total number of landslide events inventoried in the terrain unit by the time span of the investigated period. Assuming landslide recurrence was constant, and adopting a Poisson probability model, we determined the exceedance probability of having one or more landslides in each slope unit, for different periods. We obtained the probability of landslide size, a proxy for landslide magnitude, by analysing the frequency-area statistics of landslides, obtained from the multi-temporal inventory map. Lastly, assuming independence, we determined landslide hazard for each slope unit as the joint probability of landslide size, of landslide temporal occurrence, and of landslide spatial occurrence.
\end{abstract}

\section{Introduction}

Prediction of landslide hazard involves determining "where" landslides are expected, "when" or how frequently they will occur, and the "magnitude" of the landslides, i.e., how large or destructive the slope failures will be. Several methods have been proposed to evaluate where landslides are expected (e.g., Carrara, 1983; Carrara et al., 1991, 1995; van

Correspondence to: F. Guzzetti

(fausto.guzzetti@irpi.cnr.it)
Westen, 1994; Soeters and van Westen, 1996; Chung and Fabbri, 1999; Guzzetti et al., 1999, and references herein). To predict the location of future landslides, these methods use statistical classification techniques and exploit the known, inferred, or expected relationship between past landslides in an area and a set of geo-environmental thematic variables in the same area. Attempts have been made to predict "when" landslides will occur by determining the probability of landslide occurrence in a given period (e.g., Keaton et al., 1988; Lips and Wieczorek, 1990; Coe et al., 2000; Crovelli, 2000; Guzzetti et al., 2003). Most commonly, the temporal probability of landslide occurrence is obtained from catalogues of historical landslide events or multi-temporal landslide inventory maps. No single measure of landslide "magnitude" exists (Hungr, 1997). For some landslide types, landslide area is a reasonable proxy for landslide magnitude. The frequency-area statistics of landslides can be obtained from accurate landslide inventory maps (Stark and Hovius, 2001; Guzzetti et al., 2002; Malamud et al., 2004), and this information can be used as a proxy for the distribution of landslide magnitude in an area.

In this paper, we apply a recently proposed model for the probabilistic assessment of landslide hazard (Guzzetti et al., 2005). The model exploits information obtained from a multi-temporal inventory map to predict where landslides will occur, how frequently they will occur, and how large they will be. We test the model in the Collazzone area, in the central Apennines of Italy, and we discuss the results obtained.

\section{The study area}

The Collazzone area extends for $78.89 \mathrm{~km}^{2}$ in Umbria, central Italy, with elevations ranging between $145 \mathrm{~m}$ along the Tiber River flood plain and $634 \mathrm{~m}$ at Monte di Grutti (Fig. 1). The study area is bounded to the W by the Tiber River flood plain, and to the E and SE by the divides of minor tributaries of the Tiber River, including the Piedicolle, Bagno and 

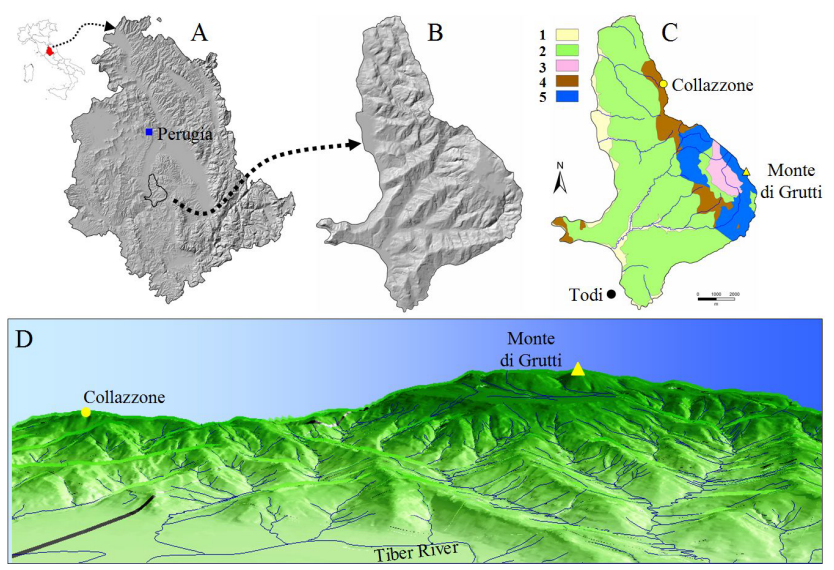

Fig. 1. Location map. (A) Shaded relief image of the Umbria Region. (B) Shaded relief image showing morphology in the Collazzone area. (C) Lithological map for the Collazzone area: (1) Alluvial deposits, Holocene in age, (2) Continental deposits, PlioPleistocene in age, (3) Travertine, Pleistocene in age, (4) Layered sandstone and marl, Miocene in age, (5) Thinly layered limestone, Lias to Oligocene in age. (D) Image showing a three-dimensional view of the study area seen from West.

Rio creeks. Landscape is predominantly hilly, and lithology and the attitude of bedding planes control the morphology of the slopes. Valleys oriented N-S are shorter, asymmetrical, and parallel to the main direction of the bedding plains, whereas valleys oriented E-W are longer, symmetrical, and mostly perpendicular to the direction of the bedding planes. In the area crop out sedimentary rocks, including (Fig. 1c): (i) recent fluvial deposits, chiefly along the main valley bottoms, (ii) continental gravel, sand and clay, Plio-Pleistocene in age, (iii) travertine deposits, Pleistocene in age, (iv) layered sandstone and marl in various percentages, Miocene in age, and (v) thinly layered limestone, Lias to Oligocene in age (Conti et al., 1977; Servizio Geologico Nazionale, 1980; Cencetti, 1990; Barchi et al., 1991). Soils in the area range in thickness from a few decimetres to more than one meter, they have a fine or medium texture, and exhibit a xenic moisture regime, typical of the Mediterranean climate. Annual rainfall averages $885 \mathrm{~mm}$, and is most abundant in the period from September to December. Landslides are abundant in the area, and range in type and volume from very old and partly dismantled large deep-seated slides to shallow slides and flows).

\section{Probabilistic model of landslide hazard}

We have recently proposed a probabilistic model for the assessment of landslide hazard (Guzzetti et al., 2005). The model is based on the definition given by Guzzetti et al. (1999), who defined landslide hazard as "the probability of occurrence within a specified period and within a given area of a potentially damaging landslide of a given magnitude". Guzzetti et al. (1999) amended the definition of land- slide hazard given by Varnes and the IAEG Commission on Landslides and other Mass-Movements (1984) to include the magnitude (i.e., the size, intensity or destructiveness) of the expected landslide event (Einstein, 1988; Canuti and Casagli, 1994; Hungr, 1997; Guzzetti et al., 2005).

In mathematical terms, the adopted definition of landslide hazard can be written:

$$
\begin{aligned}
H_{L}= & P\left[A_{L} \geq a_{L} \quad \text { in a time interval } \mathrm{t},\right. \text { given } \\
& \{\text { morphology, lithology, structure, land use, } \ldots\}]
\end{aligned}
$$

where, $A_{L}$ is the area of a landslide greater or equal than a minimum size, $a_{L}$, measured e.g., in square meters. For any given area, proposition (1) can be written as:

$H_{L}=P\left(A_{L}\right) \times P\left(N_{L}\right) \times P(S)$

that expresses landslide hazard $H_{L}$ as the conditional probability of landslide size $P\left(A_{L}\right)$, of landslide occurrence in an established period $P\left(N_{L}\right)$, and of landslide spatial occurrence $P(S)$, given the local environmental setting.

Equation (2) assumes independence of the three individual probabilities, i.e., of the three components of landslide hazard. From a geomorphological point of view, this assumption is severe and may not hold, always and everywhere (Guzzetti et al., 2005). In many areas we expect slope failures to be more frequent (time component) where landslides are more abundant and landslide area is large (spatial component). However, given the lack of understanding of the landslide phenomena, independence is an acceptable approximation that makes the problem mathematically tractable and easier to work with. In the discussion, we will examine the validity of this assumption for the study area.

In a previous work, we have proposed a method to obtain all the relevant information needed to apply the probabilistic model (Guzzetti et al., 2005). The method is based on the systematic interpretation of multiple sets of aerial photographs of different dates, aided by historical investigations and field surveys, to obtain a detailed multi-temporal landslide inventory map. The multi-temporal inventory is then exploited to: (i) obtain the spatial probability of landslide occurrence, given the local environmental setting, (ii) estimate the temporal probability of landslides, from the empirical recurrence of slope failures, and (iii) determine the probability of landslide size (area), considered a proxy for landslide magnitude.

In the following, we first describe how we have collected the landslide information in the Collazzone area. Next, we demonstrate how the landslide information can be used to determine landslide hazard. Lastly, we discuss the problems encountered and the limitations of the obtained hazard assessment.

\section{Multi-temporal landslide inventory map}

For the Collazzone area, we prepared a detailed multitemporal landslide inventory map, at 1:10000 scale, through 
Table 1. Collazzone study area, central Umbria. Aerial photographs used to prepare the multi-temporal landslide inventory map shown in Fig. 2.

\begin{tabular}{ccccc}
\hline Code & Year & Period & Type & Nominal Scale \\
\hline$A$ & 1941 & Summer & Panchromatic & $1: 18000$ \\
$B$ & 1954 & Spring-Summer & Panchromatic & $1: 33000$ \\
$C$ & 1977 & Summer & Colour & $1: 13000$ \\
$D$ & 1985 & July & Panchromatic & $1: 15000$ \\
$E$ & 1997 & April & Panchromatic & $1: 20000$ \\
\hline
\end{tabular}

the interpretation of multiple sets of aerial photographs and detailed geological and geomorphological field mapping (Fig. 2). To prepare the landslide inventory, we used five sets of aerial photographs ranging in scale from 1:13000 to 1:33 000 and covering unsystematically the period from 1941 to 1997 (Table 1). A team of two geomorphologists carried out the interpretation of the aerial photographs in the 5month period from July to November 2002. The interpreters analyzed each pair of aerial photographs using a mirror stereoscope (4× magnification) and a continue-zoom stereoscope ( $3 \times$ to $20 \times$ magnification). Both stereoscopes allowed the interpreters to map contemporaneously on the same stereo pair. The interpreters used all morphological, geological and landslide information available from published maps, and previous works carried out in the same area (e.g., Servizio Geologico Nazionale, 1980, Guzzetti and Cardinali, 1989, 1990; Antonini et al., 2002 ${ }^{1}$ ). Care was taken in identifying areas where morphology had changed in response to individual or multiple landslides, and to avoid interpretation errors due to land use modifications or to different views provided by aerial photographs taken at different dates.

The inventory map obtained from the analysis of the aerial photographs was successively updated to cover the period from 1998 to 2004 through field surveys conducted chiefly following periods of prolonged rainfall. Due to lack of aerial photographs taken after recent rainfall events, the rainfall-induced landslides were mapped directly in the field at 1:10000 scale. Colour photographs taken in the field with a handheld digital camera were used to aid the mapping and the classification of the landslides locally.

Adopting an established procedure in Umbria (Cardinali et al., 2002b; Reichenbach et al., 2005), in the multi-temporal

\footnotetext{
${ }^{1}$ Antonini, G., Ardizzone, F., Cacciano, M., Cardinali, M., Castellani, M., Galli, M., Guzzetti, F., Reichenbach, P., and Salvati, P.: Rapporto Conclusivo Protocollo d'Intesa fra la Regione dell'Umbria, Direzione Politiche Territoriali Ambiente e Infrastrutture, ed il CNR-IRPI di Perugia per l'acquisizione di nuove informazioni sui fenomeni franosi nella regione dell'Umbria, la realizzazione di una nuova carta inventario dei movimenti franosi e dei siti colpiti da dissesto, l'individuazione e la perimetrazione delle aree a rischio da frana di particolare rilevanza, e l'aggiornamento delle stime sull'incidenza dei fenomeni di dissesto sul tessuto insediativo, infrastrutturale e produttivo regionale, (in Italian), Unpublished report, May 2002, 140 p., 2002.
}

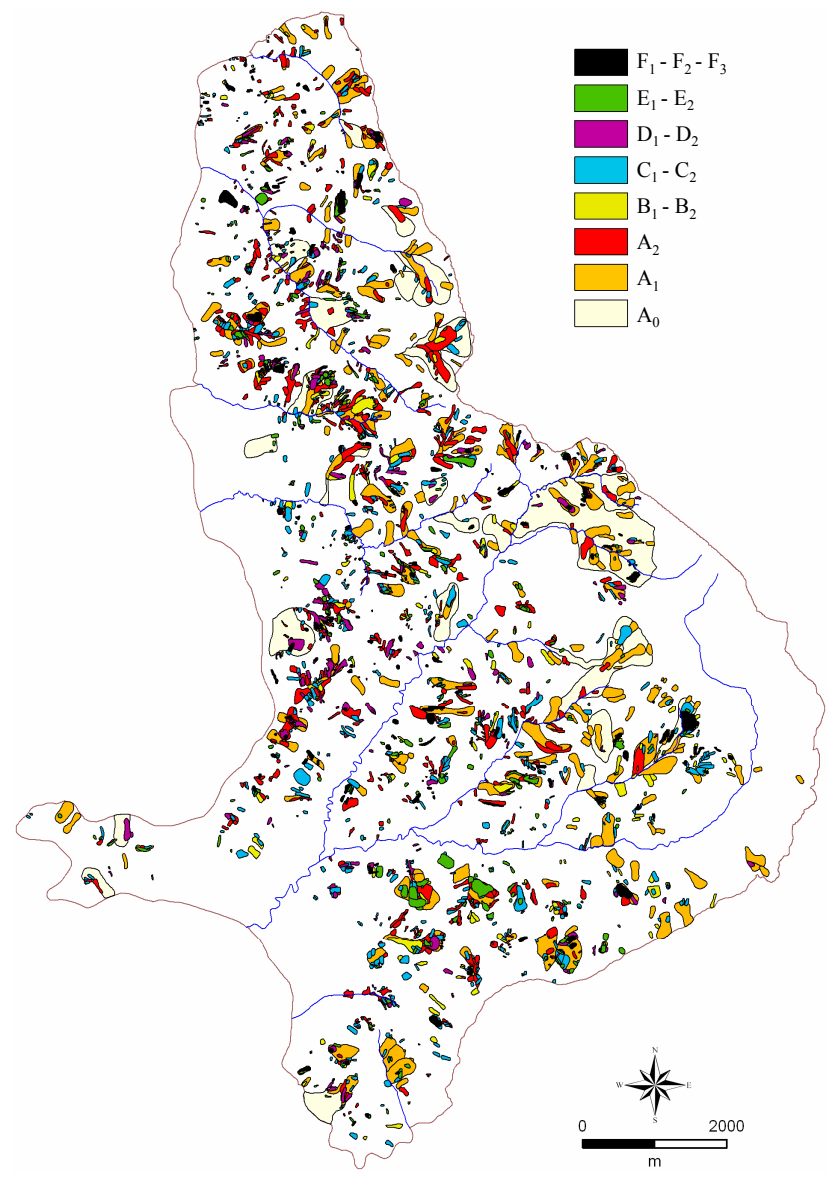

Fig. 2. Multi-temporal landslide inventory map for the Collazone area. See Fig. 1 for location. Colours show landslides of different age, inferred from the date of the aerial photographs and of field surveys. $\mathrm{A}_{0}$, very old relict landslide; $\mathrm{A}_{1}$, landslides older than 1941; $A_{2}$, active landslides in $1941 ; B_{1}-B_{2}$, landslides in the period from 1941 to $1954 ; C_{1}-C_{2}$, landslides in the period from 1954 to $1977 ; \mathrm{D}_{1}-\mathrm{D}_{2}$, landslides in the period from 1977 to $1985 ; \mathrm{E}_{1}-\mathrm{E}_{2}$, landslides in the period from 1985 to $1997 ; \mathrm{F}_{1}-\mathrm{F}_{2}-\mathrm{F}_{3}$; landslides in the period from 1998 to 2004 . See Table 2 and text for explanation.

inventory landslides were classified according to the type of movement, and the estimated age, activity and depth. Landslide type was defined according to Cruden and Varnes (1996) and the WP/WLI (1990). For deep-seated slope failures, the landslide crown was mapped separately from the deposit. The distinction was not made for shallow landslides. Uncertainty exists in the determination of landslide depth based on the morphological appearance of the landslide terrain ascertained from the aerial photographs. Landslide age, activity, and depth were estimated based on the type of movement, the morphological characteristics and appearance of the landslides on the aerial photographs, the local lithological and structural setting, and the date of the aerial photographs or the field surveys. Landslide age was defined as very old (relict), old (predating 1941) or recent (in the period from 1941 to 2004), using photo-interpretation criteria and field evidence, despite ambiguity in the definition of the 
age of a mass movement based on its appearance (McCalpin, 1984).

In each of the five sets of aerial photographs used to prepare the multi-temporal inventory, we separated landslides that appeared "fresh" on the aerial photographs, from the other landslides. We assigned the "fresh" slope failures the date (i.e., year) of the aerial photographs used to identify the landslides. The other slope failures (i.e., the "non-fresh" landslides) were attributed to the period between two successive sets of aerial photographs. The latter groups include landslides that exhibited morphological changes with respect to one or more of the older sets of aerial photographs. Landslides mapped in the field after rainfall events in the period between 1998 and 2004 were attributed to three different dates, depending on the dates of the field surveys.

In the multi-temporal inventory (Fig. 2), very old (relict) landslides include deep-seated slope failures with an area $A_{L}>6.3 \times 10^{4} \mathrm{~m}^{2}$ (i.e., $>6.3 \mathrm{ha}$ ) and an estimated volume $V_{L}>\times 10^{6} \mathrm{~m}^{3}$. These very old failures are present mostly in the head section of minor catchments, and are largely controlled by lithology, structure and the attitude of the bedding planes. In places, the very old landslides are covered by multiple generations of younger landslides that have dismantled and cancelled the older landslides, making their recognition problematic. Old landslides include deep-seated and shallow slope failures. The old, deep-seated failures are mostly rock/earth slides and complex earth slides - earth flows, extending from less than $1.0 \times 10^{4} \mathrm{~m}^{2}$ ( 1 ha) to more than $1.7 \times 10^{5} \mathrm{~m}^{2}(17 \mathrm{ha})$. The morphology of the old landslides is similar to the morphology of the relict landslides, but the old failures are less affected by more recent slope failures. For this reason, recognition of old landslides is easier, in the field and from the aerial photographs. The old shallow landslides are mostly slide and flow, extending in area from less than $1.0 \times 10^{3} \mathrm{~m}^{2}$ to $2.8 \times 10^{4} \mathrm{~m}^{2}$ (2.8 ha). Recent landslides in the multi-temporal inventory consist chiefly of shallow failures that occurred in the 64-year period from 1941 to 2004, and include active slope failures at the date of the field surveys.

Table 2 summarizes statistics for the landslides in the multi-temporal inventory map. The entire inventory, covering an undetermined period from pre-1941 to $2004\left(\mathrm{~A}_{0}-\right.$ $\mathrm{F}_{3}$ in Table 2), shows 2787 landslides, including 27 very old and relict landslides, for a total mapped landslide area of $22.79 \mathrm{~km}^{2}$, which corresponds to a landslide density of 35.32 slope failures per square kilometre. Due to geographical overlap of landslides of different periods, the total area affected by landslides is $16.69 \mathrm{~km}^{2}, 21.16 \%$ of the studied area. Mapped landslides extend in size from $51 \mathrm{~m}^{2}$ to $1.45 \mathrm{~km}^{2}$, and the most represented (i.e., numerous, abundant) failures shown in the map have an area of about $8.15 \times 10^{2} \mathrm{~m}^{2}$. The inventory lists 2490 landslides $(89.34 \%)$ for which the date or the period of occurrence was determined $\left(\mathrm{A}_{2}-\mathrm{F}_{3}\right.$ in Table 2). These landslides have an average landslide size of $4.19 \times 10^{3} \mathrm{~m}^{2}$, for a total landslide area of $10.24 \mathrm{~km}^{2}$, covering $7.81 \mathrm{~km}^{2}$ (9.89\% of the study area). These figures compare with $297(10.66 \%)$ old and very old landslides whose age remained undetermined but was older than 1941. The old and very old landslides have an average area of $4.15 \times 10^{4} \mathrm{~m}^{2}$, for a total landslide area of $12.34 \mathrm{~km}^{2}$, covering $11.43 \mathrm{~km}^{2}$ (14.48\% of the study area). We attribute the largest abundance of landslides in the period from 1941 to 2004 to incompleteness of the multi-temporal map before 1941. We further attribute the large average landslide area of the very old and old landslides to amalgamation of smaller landslides into larger landslide areas. Very old and relict landslides may have also formed under different and more severe climatic or seismic conditions (Carrara et al., 1995).

\section{Landslide hazard assessment}

The Collazzone study area was first subdivided into slope units to determine landslide hazard. Slope units are terrain units bounded by drainage and divide lines (Carrara et al., 1991). Starting from a digital terrain model with a ground resolution of $10 \mathrm{~m} \times 10 \mathrm{~m}$ and a simplified representation of the main drainage lines, specific software partitioned the study area into 894 slope units. For each slope unit, the software computed 21 morphometric and hydrological parameters useful to explain the spatial distribution of landslides. To better represent the distinct limit between the hills and the Tiber River flood plain, avoiding the problem of slope units characterized by two distinct terrain types (e.g., sloping terrain and the flat terrain in the flood plain), a synthetic river channel was drawn in correspondence to the brake in slope.

\subsection{Probability of landslide size}

We ascertained the probability of landslide area, a proxy for landslide magnitude, for two datasets: (i) the entire multitemporal inventory listing 2787 landslides $\left(\mathrm{A}_{0}-\mathrm{F}_{3}\right.$ in Table 2), and (ii) the multi-temporal inventory covering the 64-year period from 1941 to 2004, listing 2490 landslides $\left(\mathrm{A}_{2}-\mathrm{F}_{3}\right.$ in Table 2$)$. We obtained the area of the individual landslides in the GIS. Care was taken to calculate the exact size of each landslide, avoiding topological and graphical problems related to the presence of smaller landslides inside larger mass movements. For the deep-seated landslides, we merged the crown area and the deposit, and we used the total landslide area in the analysis.

Fig. 3I shows the obtained probability densities of landslide area in the Collazzone area. Four estimates are shown: two for the entire landslide dataset $\left(\mathrm{A}_{0}-\mathrm{F}_{3}\right)$, and two for the reduced landslide dataset $\left(\mathrm{A}_{2}-\mathrm{F}_{3}\right)$. To determine the probability densities we adopted the double-Pareto distribution of Stark and Hovius (2001) and the inverse Gamma distribution of Malamud et al. (2004). Inspection of Fig. 3I and Table 3 reveals that in the Collazzone area the two probability distributions provide similar results, differing chiefly for landslides smaller than $\sim 500 \mathrm{~m}^{2}$. Further inspection of Fig. 3I indicates that a significant difference exists in the slope of the tail of the distribution, when landslides of the two considered periods are compared. Based on the entire multi-temporal inventory $\left(\mathrm{A}_{0}-\mathrm{F}_{3}\right)$, the inverse Gamma 
Table 2. Collazzone study area, central Umbria. Landslide size and abundance. Figures obtained from the multi-temporal inventory map shown in Fig. 2. Inventory type: P, obtained from the systematic interpretation of stereoscopic aerial photographs; F, obtained through direct field mapping. See Table 1 for date of the aerial photographs used to complete the inventory. * Landslide age estimated from the date of the aerial photographs and the morphological appearance of the landslide. ** Percentage of landslide area with respect to the total area covered by landslides $\left(\mathrm{A}_{0}-\mathrm{F}_{3}\right)$.

\begin{tabular}{|c|c|c|c|c|c|c|c|c|c|}
\hline \multicolumn{2}{|c|}{ Inventory } & \multirow[b]{2}{*}{ Estimated landslide age* } & \multicolumn{2}{|c|}{ Landslide } & \multicolumn{5}{|c|}{ Landslide Area } \\
\hline Ref. & Type & & $\begin{array}{c}\text { Number } \\
\#\end{array}$ & $\begin{array}{c}\text { Density } \\
\# / \mathrm{km}^{2}\end{array}$ & $\begin{array}{l}\text { Total } \\
\mathrm{km}^{2}\end{array}$ & $\begin{array}{c}\text { Percent** } \\
\%\end{array}$ & $\begin{array}{c}\text { Min } \\
\mathrm{m}^{2}\end{array}$ & $\begin{array}{c}\text { Mean } \\
\mathrm{m}^{2}\end{array}$ & $\begin{array}{c}\operatorname{Max} \\
\mathrm{m}^{2}\end{array}$ \\
\hline $\mathrm{A}_{0}$ & $\mathrm{P}$ & very old, relict & 27 & 0.34 & 5.72 & 34.27 & 63092 & 211949 & 1459949 \\
\hline $\mathrm{A}_{1}$ & $\mathrm{P}$ & older than 1941 & 270 & 3.42 & 6.62 & 39.66 & 831 & 24555 & 173518 \\
\hline $\mathrm{A}_{2}$ & $\mathrm{P}$ & 1941 & 713 & 9.04 & 4.09 & 24.50 & 215 & 6005 & 75256 \\
\hline $\mathrm{B}_{1}$ & $\mathrm{P}$ & $1941-1954$ & 63 & 0.79 & 0.42 & 2.52 & 864 & 6722 & 22780 \\
\hline $\mathrm{B}_{2}$ & $\mathrm{P}$ & 1954 & 97 & 1.23 & 0.71 & 4.25 & 772 & 7288 & 49706 \\
\hline $\mathrm{C}_{1}$ & $\mathrm{P}$ & 1954-1977 & 409 & 5.18 & 1.49 & 8.93 & 225 & 3649 & 38712 \\
\hline $\mathrm{C}_{2}$ & $\mathrm{P}$ & 1977 & 252 & 3.19 & 0.69 & 4.13 & 156 & 2761 & 18407 \\
\hline $\mathrm{D}_{1}$ & $\mathrm{P}$ & 1977-1985 & 105 & 1.33 & 0.62 & 3.71 & 782 & 5892 & 33351 \\
\hline $\mathrm{D}_{2}$ & $\mathrm{P}$ & 1985 & 135 & 1.71 & 0.45 & 2.69 & 103 & 3342 & 27018 \\
\hline $\mathrm{E}_{1}$ & $\mathrm{P}$ & 1985-1997 & 63 & 0.79 & 0.27 & 1.62 & 320 & 4253 & 35733 \\
\hline $\mathrm{E}_{2}$ & $\mathrm{P}$ & 1998 & 413 & 5.23 & 0.78 & 4.67 & 78 & 1880 & 44335 \\
\hline $\mathrm{F}_{1}$ & $\mathrm{~F}$ & 1997-2003 & 17 & 0.21 & 0.07 & 0.42 & 136 & 4134 & 26011 \\
\hline $\mathrm{F}_{2}$ & $\mathrm{~F}$ & May 2004 & 70 & 0.89 & 0.27 & 1.62 & 97 & 3811 & 31909 \\
\hline $\mathrm{F}_{3}$ & $\mathrm{~F}$ & Dec 2004 & 153 & 1.94 & 0.38 & 2.28 & 51 & 2517 & 47884 \\
\hline $\mathrm{A}_{0}-\mathrm{A}_{1}$ & & very old and older than 1941 & 297 & 3.76 & 11.43 & 68.48 & 831 & 41500 & 1459949 \\
\hline $\mathrm{A}_{0}-\mathrm{F}_{3}$ & & very old to Dec 2004 & 2787 & 35.32 & 16.69 & 100 & 51 & 8177 & 1459949 \\
\hline $\mathrm{A}_{1}-\mathrm{F}_{3}$ & & older than 1941 to Dec 2004 & 2760 & 34.98 & 12.51 & 74.95 & 51 & 6184 & 173518 \\
\hline $\mathrm{A}_{2}-\mathrm{E}_{2}$ & & 1941 to April 1997 & 2250 & 28.52 & 7.42 & 44.45 & 78 & 4318 & 75256 \\
\hline $\mathrm{F}_{1}-\mathrm{F}_{3}$ & & 1998 to Dec 2004 & 240 & 3.04 & 0.69 & 4.13 & 51 & 3009 & 47884 \\
\hline $\mathrm{A}_{2}-\mathrm{F}_{3}$ & & 1941 to Dec 2004 & 2490 & 31.56 & 7.81 & 46.79 & 51 & 4193 & 75256 \\
\hline
\end{tabular}

Table 3. Collazzone study area, central Umbria. DP, double Pareto distribution (Stark and Hovius, 2001); IG, inverse Gamma distribution (Malamud et al., 2004).

\begin{tabular}{|c|c|c|c|c|c|}
\hline \multirow{2}{*}{ Data set } & \multirow{2}{*}{ Period } & \multicolumn{2}{|c|}{$\alpha$} & \multicolumn{2}{|c|}{ Size of most abundant landslide $\left(\mathrm{m}^{2}\right)$} \\
\hline & & DP & IG & DP & IG \\
\hline$A_{0}-F_{3}$ & very old to Dec 2004 & 2.15 & 2.18 & 816 & 816 \\
\hline$A_{2}-F_{3}$ & 1941 to Dec 2004 & 2.48 & 2.54 & 881 & 1019 \\
\hline
\end{tabular}

and the double Pareto distributions predict a significantly larger proportion of large $\left(A_{L}>1 \times 10^{4} \mathrm{~m}^{2}\right)$ and very large $\left(A_{L}>1 \times 10^{6} \mathrm{~m}^{2}\right)$ landslides, when compared to the estimates obtained from the reduced landslide dataset $\left(\mathrm{A}_{2}-\mathrm{F}_{3}\right)$. We attribute the difference to the presence of a few very large and relict landslides in dataset $\mathrm{A}_{0}-\mathrm{F}_{3}$, which are not present in dataset $\mathrm{A}_{2}-\mathrm{F}_{3}$.

Figure 3II shows the probability of landslide size, i.e., the probability that a landslide will have an area smaller than a given size (left axis), or the probability that a landslide will have an area that exceeds a given size (right axis). Using dataset $\mathrm{A}_{2}-\mathrm{F}_{3}$, the probability that a landslide exceeds $1 \times 10^{3} \mathrm{~m}^{2}$ (i.e., slightly larger than the area of the most abundant landslide mapped in the multi-temporal inventory) is $\sim 0.80$, and the probability that a landslide exceeds $1 \times 10^{4} \mathrm{~m}^{2}$ is $\sim 0.10$. We will use these statistics to ascertain landslide hazard.

\subsection{Frequency of landslide occurrence}

The model adopted to assess landslide hazard requires an estimate of the temporal probability of slope failures (Guzzetti et al., 2005). To obtain an estimate of the frequency of landslide occurrence, we counted the number of landslides shown in the multi-temporal inventory in each slope unit. Considering only the recent landslides $\left(\mathrm{A}_{2}-\mathrm{F}_{3}\right)$, we prepared a map of the total number of landslide events (i.e., of landslide occurrences) in the 64-year period between 1941 and 2004 , the dates of the oldest aerial photographs and the most recent field survey. For each slope unit, based on the past rate 
Table 4. Number and percentage of slope units, and total area and percentage of slope units, in five classes of the probability of temporal landslide occurrence (see Fig. 4). Square bracket indicates class limit is included; round bracket indicates class limit is not included. Temporal probability of landslide occurrence obtained exploiting the multi-temporal landslide inventory map (Fig. 2) and adopting a Poisson probability model. See text for explanation.

\begin{tabular}{|c|c|c|c|c|c|c|c|c|c|c|c|c|c|c|c|c|c|c|c|c|}
\hline \multirow[b]{3}{*}{ years } & \multicolumn{4}{|c|}{$[0-0.2)$} & \multicolumn{4}{|c|}{$[0.2-0.4)$} & \multicolumn{4}{|c|}{$[0.4-0.6)$} & \multicolumn{4}{|c|}{$[0.6-0.8)$} & \multicolumn{4}{|c|}{$[0.8-1.0]$} \\
\hline & \multicolumn{2}{|c|}{ number } & \multicolumn{2}{|c|}{ area } & \multicolumn{2}{|c|}{ number } & \multicolumn{2}{|c|}{ area } & \multicolumn{2}{|c|}{ number } & \multicolumn{2}{|c|}{ area } & \multicolumn{2}{|c|}{ number } & \multicolumn{2}{|c|}{ area } & \multicolumn{2}{|c|}{ number } & \multicolumn{2}{|c|}{ area } \\
\hline & $\#$ & $\%$ & $\mathrm{~km}^{2}$ & $\%$ & $\#$ & $\%$ & $\mathrm{~km}^{2}$ & $\%$ & $\#$ & $\%$ & $\mathrm{~km}^{2}$ & $\%$ & $\#$ & $\%$ & $\mathrm{~km}^{2}$ & $\%$ & $\#$ & $\%$ & $\mathrm{~km}^{2}$ & $\%$ \\
\hline 5 & 581 & 64.99 & 36.37 & 46.10 & 279 & 31.21 & 34.03 & 43.14 & 34 & 3.80 & 8.49 & 10.76 & - & - & - & - & - & - & - & - \\
\hline 10 & 477 & 53.36 & 28.41 & 36.01 & 220 & 24.61 & 18.21 & 23.08 & 130 & 14.54 & 16.92 & 21.45 & 67 & 7.49 & 15.35 & 19.46 & - & - & - & - \\
\hline 25 & 302 & 33.78 & 16.37 & 20.75 & 175 & 19.57 & 12.04 & 15.26 & 104 & 11.63 & 7.96 & 10.09 & 187 & 20.92 & 19.30 & 24.46 & 126 & 14.09 & 23.22 & 29.43 \\
\hline 50 & 235 & 26.28 & 12.89 & 16.34 & 67 & 7.49 & 3.48 & 4.41 & 175 & 19.57 & 12.04 & 15.26 & 104 & 16.63 & 7.95 & 10.08 & 313 & 35.01 & 45.52 & 53.90 \\
\hline
\end{tabular}

Table 5. Variables entered into the seven discriminant models of landslide susceptibility (see Fig. 5). (A) Model obtained using landslides identified in the period $\mathrm{A}_{1}$; (B) model obtained using landslides in the period $\mathrm{A}_{1}-\mathrm{A}_{2} ;(\mathrm{C})$ model obtained using landslides in the period $\mathrm{A}_{1}-$ $\mathrm{B}_{2}$; (D) model obtained using landslides in the period $\mathrm{A}_{1}-\mathrm{C}_{2} ;(\mathrm{E})$ model obtained using landslides in the period $\mathrm{A}_{1}-\mathrm{D}_{2}$; (F) model obtained using landslides in the period $\mathrm{A}_{1}-\mathrm{E}_{2} ;(\mathrm{G})$ model obtained using landslides in the period $\mathrm{A}_{1}-\mathrm{F}_{3}$. Standard discriminant function coefficients (SDFC) show the relative importance of each variable in the discriminant function. Coefficients shown in bold are strongly associated with the presence/absence of landslides. Positive coefficients are correlated to the absence of landslides. Negative coefficients are correlated to the presence of landslides.

\begin{tabular}{|c|c|c|c|c|c|c|c|c|}
\hline \multirow{2}{*}{ Variable description } & \multirow{2}{*}{ Variable } & \multicolumn{7}{|c|}{ Model SDFC } \\
\hline & & A & $B$ & $C$ & $D$ & E & $F$ & G \\
\hline Drainage channel order & ORDER & & 162 & 280 & .181 & 148 & 146 & .138 \\
\hline Drainage channel length & LINK_LEN & -.425 & & & -.198 & & & \\
\hline Slope unit area & SLO_AREA & & -.358 & -.269 & & -.255 & -.264 & -.247 \\
\hline Slope unit mean elevation & ELV_M & -.673 & & & & & & \\
\hline Slope unit terrain elevation standard dev. & ELV_STD & & -.250 & -.362 & -.307 & -.372 & -.379 & -.377 \\
\hline Slope unit mean terrain gradient & SLO_ANG & -.385 & -.695 & & -.675 & & & -.392 \\
\hline Slope unit terrain gradient standard dev. & ANG_STD & & .310 & & .381 & .308 & .298 & .355 \\
\hline Slope unit length & SLOLLEN & -.230 & & & -.210 & & -.213 & \\
\hline Slope unit length standard deviation & LEN_STD & & & & & & .257 & \\
\hline Slope unit terrain gradient (lower portion) & ANGLE1 & & & -.327 & & -.192 & & \\
\hline Slope unit terrain gradient (middle portion) & ANGLE2 & & .343 & & .276 & & & \\
\hline Slope unit terrain gradient (upper portion) & ANGLE3 & & -.349 & & -.390 & -.517 & -.549 & -.365 \\
\hline Concave profile down slope & CONV & .121 & & & & & & \\
\hline Convex-concave profile & COC_COV & & & .137 & & & & \\
\hline Complex slope profile & $\mathrm{CC}$ & & .499 & & .471 & .442 & .583 & .436 \\
\hline Recent alluvial deposits & ALLUVIO & & .196 & .324 & & .218 & .283 & .216 \\
\hline Sandstone & AREN & 164 & & & & & & \\
\hline Limestone & CARBO & .836 & .623 & .769 & .699 & .770 & .784 & .825 \\
\hline Travertine & TREVERTI & .372 & & .238 & & .126 & .162 & .152 \\
\hline Clay & ARGILLA & & & -.102 & -.128 & -.116 & & \\
\hline Gravel & GHIAIA & & & & & & & .100 \\
\hline Continental deposits & CONTI & & -.144 & & -.178 & & & \\
\hline Marl & MARNE & & & & & & 109 & .113 \\
\hline Sand & SABBIA & & -.165 & & -.108 & & & \\
\hline Forested area & BOSCO & & .151 & & .227 & .277 & & .355 \\
\hline Cultivated area & SA & -.190 & & -.101 & & & .295 & \\
\hline Fruit trees and vineyards & FRUTT & & & & .101 & & & .106 \\
\hline Bedding dipping into of the slope & REG & & .260 & & & & & \\
\hline Bedding dipping out of the slope & FRA & -.582 & & -.277 & -.288 & -.241 & -.152 & -.160 \\
\hline Bedding dipping across the slope & TRA & -.219 & & -.159 & & & & \\
\hline Slope unit facing S-SE & TR2 & .188 & .325 & .284 & 186 & .233 & .273 & .275 \\
\hline Very old (relict) landslide $\left(\mathrm{A}_{0}\right)$ & FRA_OLD & -.159 & -.164 & & & & & \\
\hline Number of variables in the model & & 13 & 16 & 13 & 17 & 14 & 15 & 16 \\
\hline
\end{tabular}



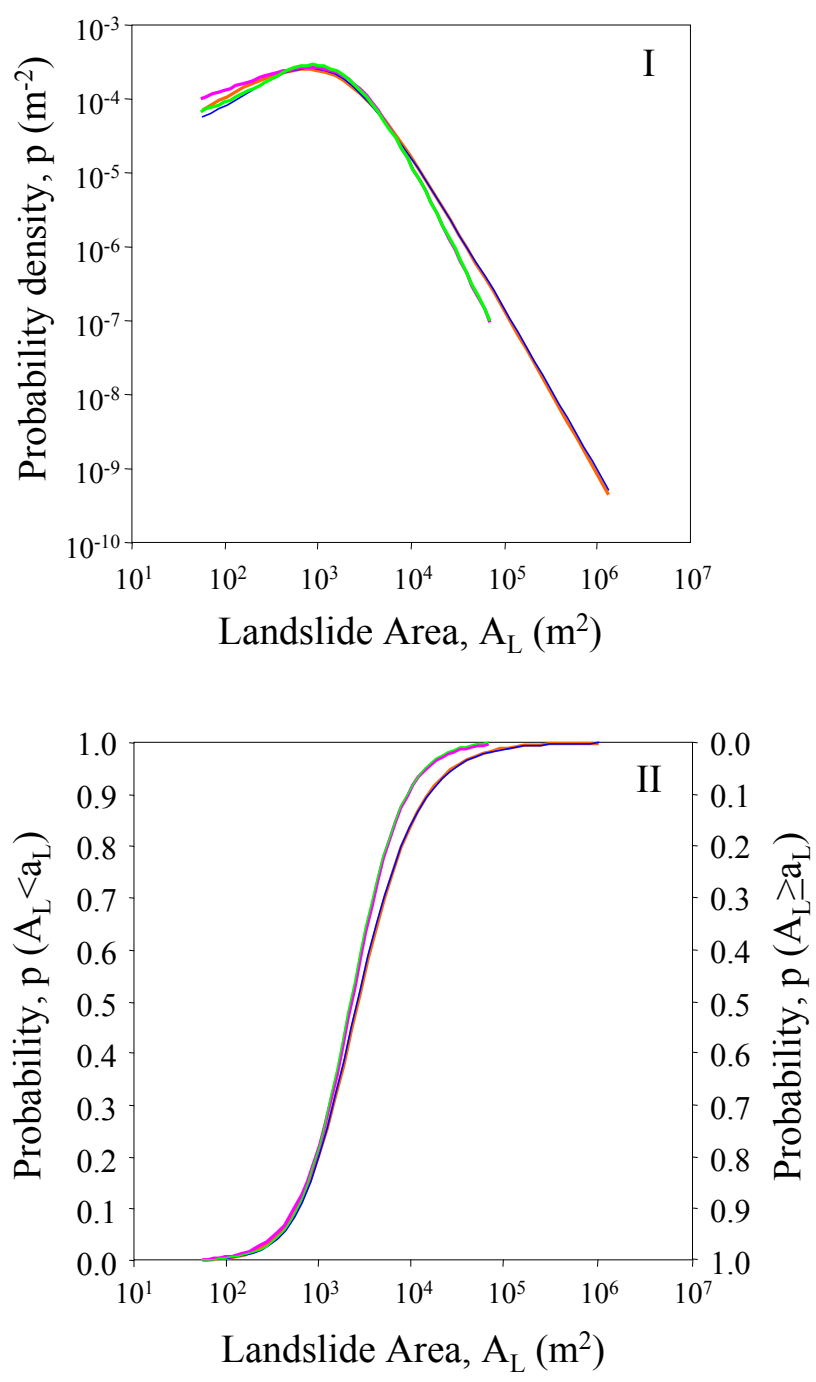

Double Pareto Inverse Gamma

$$
\begin{array}{rr}
\mathrm{A}_{0}-\mathrm{F}_{3} & \mathrm{~A}_{0}-\mathrm{F}_{3} \\
\mathrm{~A}_{2}-\mathrm{F}_{3} & \mathrm{~A}_{2}-\mathrm{F}_{3}
\end{array}
$$

Fig. 3. Probability density (I) and probability (II) of landslide area. Blue and orange lines show inverse Gamma distribution (blue line, Malamud et al., 2004) and double Pareto distribution (orange line, Stark and Hovius, 2001) for landslides in the period from very old to $2004\left(\mathrm{~A}_{0}-\mathrm{F}_{3}\right)$. Green and pink lines are inverse Gamma distribution (green) and double Pareto distribution (pink) for the inventory covering the period from 1941 to $2004\left(\mathrm{~A}_{2}-\mathrm{F}_{3}\right)$.

of landslide occurrence we obtained the landslide recurrence, i.e., the expected time between successive failures. Knowing the mean recurrence interval of landslides in each mapping unit (from 1941 to 2004), assuming the rate of slope failures will remain the same for the future, and adopting a Poisson probability model (Crovelli, 2000; Guzzetti et al., 2003, 2005), we then computed the exceedance probability of having one or more landslides in each slope unit. Fig-

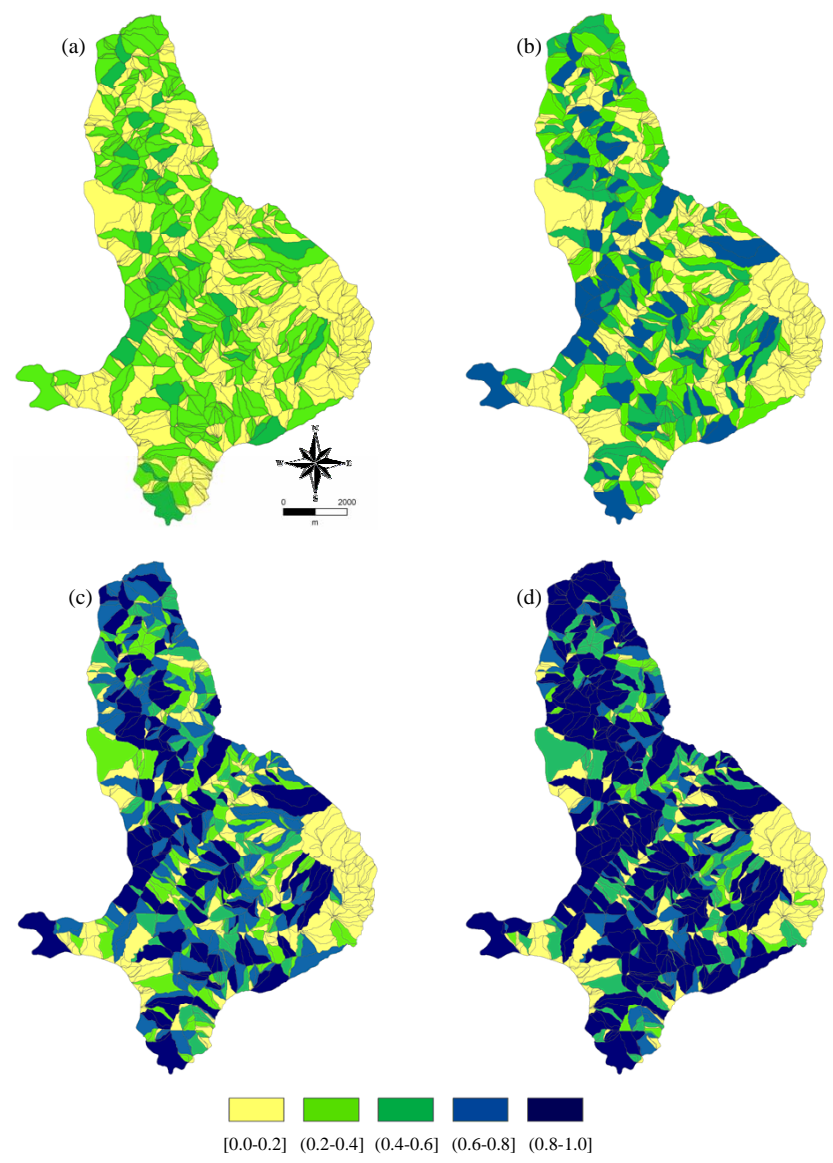

Fig. 4. Exceedance probability of landslide temporal occurrence obtained computing the mean recurrence interval of past landslide events from the multi-temporal inventory map (Fig. 2), assuming it will remain the same for the future, and adopting a Poisson probability model. Exceedance probability shown for four periods: (a) 5 years, (b) 10 years, (c) 25 years, and (d) 50 years. Square bracket indicates class limit is included; round bracket indicates class limit is not included.

ure 4 shows the exceedance probability of landslide occurrence for four different periods, from 5 to 50 years. We will use these statistics to ascertain landslide hazard. Table 4 lists the number and total area of slope units in five classes of the estimated probability of temporal landslide occurrence.

\subsection{Landslide susceptibility}

The adopted hazard model requires a probabilistic estimate of the spatial occurrence of landslides (Guzzetti et al., 2005). We obtained landslide susceptibility through discriminant analysis of 46 thematic variables, including morphology (26 variables derived from a $10 \mathrm{~m} \times 10 \mathrm{~m}$ DTM), lithology (9 variables), structure ( 3 variables), land use ( 7 variables), and the presence of large relict landslides (1 variable). In a GIS, we computed the percentage of the individual thematic variables in each slope unit. The obtained values became the independent (explanatory) variables in the multivariate statistical analysis. We then computed the percentage of landslide 

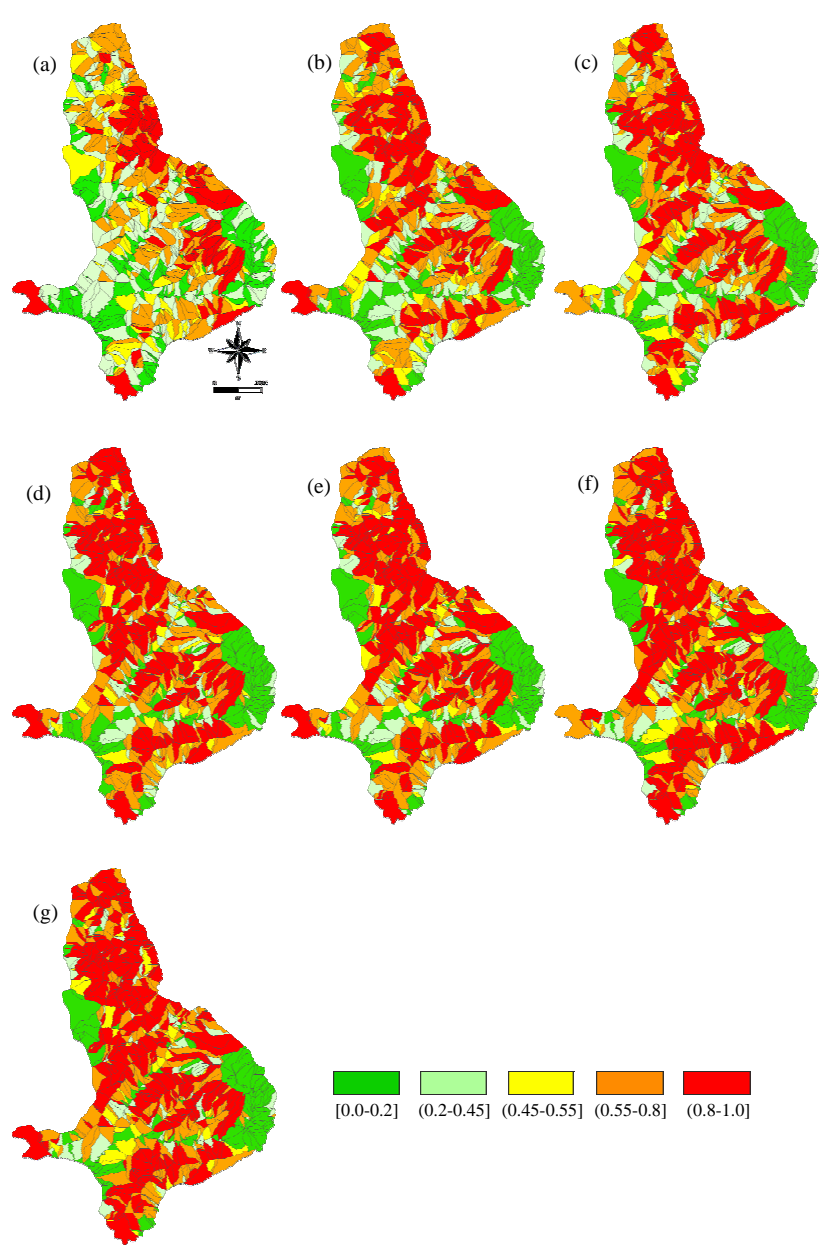

Fig. 5. Landslide susceptibility models obtained through discriminate analysis of the same set of independent thematic variables (Table 5) and changing the landslide inventory map (dependent variable, Fig. 2 and Table 2). (a) Model obtained using landslides identified in the period $\mathrm{A}_{1}$; (b) model obtained using landslides in the period $\mathrm{A}_{1}-\mathrm{A}_{2}$; (c) model obtained using landslides in the period $\mathrm{A}_{1}-\mathrm{B}_{2}$; (d) model obtained using landslides in the period $\mathrm{A}_{1}-\mathrm{C}_{2}$; (e) model obtained using landslides in the period $\mathrm{A}_{1}-\mathrm{D}_{2}$; (f) model obtained using landslides in the period $\mathrm{A}_{1}-\mathrm{E}_{2} ;(\mathrm{g})$ model obtained using landslides in the period $\mathrm{A}_{1}-\mathrm{F}_{3}$. Colours indicate spatial probability in 5 classes. Square bracket indicates class limit is included; round bracket indicates class limit is not included.

area in each slope unit. We selected a threshold of $3 \%$ of landslide area to determine if a slope unit was: (i) free of landslides $(\leq 3 \%)$ group 0 , or (ii) contained slope failures ( $>3 \%$ ) group 1. We selected this threshold to account for possible mapping, drafting and digitizing errors in the compilation of the landslide inventory map.

Figure 5 shows seven susceptibility maps obtained from seven statistical models prepared using the same set of environmental variables, and changing incrementally the landslide inventory map. We prepared the first susceptibility model (Fig. 5a) using only the old landslides $\left(\mathrm{A}_{1}\right.$ in Table 2). We then added to the inventory the landslides identified as active in the 1941 aerial photographs and we obtained a new estimate of the probability of spatial landslide occurrence (Fig. 5b). We repeated the same procedure adding the slope failures that we identified and mapped using the 1954, 1977, 1985, and 1997 aerial photographs (Figs. 5c-f). To prepare the last model (Fig. 5g), we added all the slope failures mapped in the field in the period from 1998 to 2004.

At each step, we obtained a different susceptibility map, i.e., a different estimate of the probability of landslide spatial occurrence, $P(S)$. At each step, a different discriminant function selected different variables as the best predictors of landslide occurrence. Table 5 lists the variables entered in the seven discriminant models. In this table, the standard discriminant function coefficients (SDFC) show the relative importance of each variable in the discriminant function as a predictor of slope stability or instability. Variables with large coefficients, in absolute value, (shown in bold), are strongly associated with the presence/absence of landslides. In particular, positive coefficients are correlated to the absence of landslides, and negative coefficients are correlated to the presence of landslides.

Inspection of Table 5 reveals that two variables (CARBO and TR2) entered all seven discriminant models, and five variables (ORDER, ELV_STD, CARBO, FRA, TR2) entered six discriminant models. Further inspection of Table 5 indicates that eleven of the 46 thematic variables $(23.9 \%)$ entered at least five susceptibility models, confirming their importance in explaining the geographical distribution of past landslides. These variable include morphological (ORDER, SLO_AREA, ELV_STD, ANG_STD, ANGLE3, CC, TR2), lithological (ALLUVIO, CARBO, TRAVERTI), and structural (FRA) conditions. Five variables entered at least five models with large standard discriminant function coefficients $(\mathrm{SDFC}>|0.300|)$. Of the latter variables, three are associated with stable conditions (ANG_STD, CC, CARBO), and two variables are associated with unstable slope conditions (ELV_STD, ANGLE3).

Figure 6 compares the fitting performances of the seven susceptibility models. By upgrading the landslide inventory, the total number of mapping units correctly classified - a measure of model fit - increased from $73.8 \%$ to $83.0 \%$. This confirms that a more complete inventory improves the model fit (Guzzetti et al., 2005). Further inspection of Fig. 6 reveals that the two most significant improvements in terms of fitting performance occurred: (i) when the 713 landslides identified as active in the 1941 aerial photographs $\left(\mathrm{A}_{2}\right)$ were added to the inventory $A_{1}$, and (ii) when the 413 landslides identified as active in the $1997\left(E_{2}\right)$ aerial photographs were added to the inventory $A_{1}-E_{1}$. These new landslides represent an increase of $70.59 \%$ in number and $18.92 \%$ in area $\left(\mathrm{A}_{2}\right)$, and $16.21 \%$ in number and $1.58 \%$ in area $\left(E_{2}\right)$, with respect to the previous inventories, respectively.

Overall, by adding new landslides, the number of unstable terrain units correctly classified by the models increased $9.7 \%$, and the number of unstable slope units wrongly attributed to the stable class decreased $10.3 \%$. By adding the 240 landslides mapped in the field in the period from 1998 


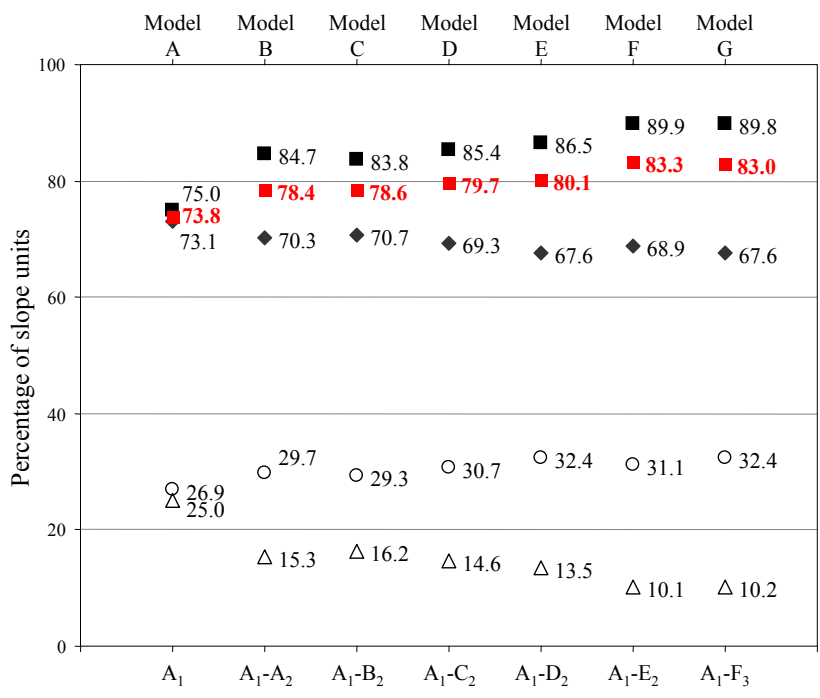

Fig. 6. Degree of fit for seven landslide susceptibility models. $x-$ axis identifies the model, and y-axis shows percentage of mapping units in each model. Large red squares: overall percentage of mapping units correctly classified by the 7 susceptibility models. Black and open symbols show mapping units correctly and incorrectly classified, respectively. Black diamonds show percentage of mapping units free of landslides classified as stable. Black squares show percentage of mapping units having landslides classified as unstable. Open circles show percentage of mapping units free of landslides misclassified as unstable (type 1 error). Open triangles show percentage of mapping units having landslides misclassified as stable (type 2 error).

to 2004 , the model fitting performance did not improve; it decreased $0.3 \%$ (from $83.3 \%$ to $83.0 \%$ ).

Based on the results shown in Fig. 6, we selected model E (Fig. 5e) as the predictor of landslide susceptibility in the Collazzone area, and we adopted this model to determine landslide hazard. We selected model $\mathrm{E}$ as a compromise between model performance and the amount of landslide information used to construct the model. Model E was prepared using 2044 landslides (74.1\%) in the period from pre-1941 to $1985\left(\mathrm{~A}_{1}-\mathrm{D}_{2}\right)$, which allowed using a considerable number of landslides (716, 25.9\%) occurred in the period from 1985 to $2004\left(\mathrm{E}_{1}-\mathrm{F}_{3}\right)$ for the validation of the prediction skill of the susceptibility model.

For the selected susceptibility model, we attempted an assessment of the uncertainty (i.e., the error) associated with the susceptibility estimate. To accomplish this, we prepared an ensemble of 50 susceptibility models obtained from the same set of 46 independent thematic variables and the same multi-temporal landslide map $\left(\mathrm{A}_{1}-\mathrm{E}_{2}\right)$, but using 50 different and randomly selected subsets of slope units. Each subset contained 760 slope units, i.e., $85 \%$ of the entire set of slope units. Next, we prepared a landslide susceptibility model for each subset, obtaining 50 different susceptibility models, i.e., 50 forecasts of landslide susceptibility for the Collazzone area.

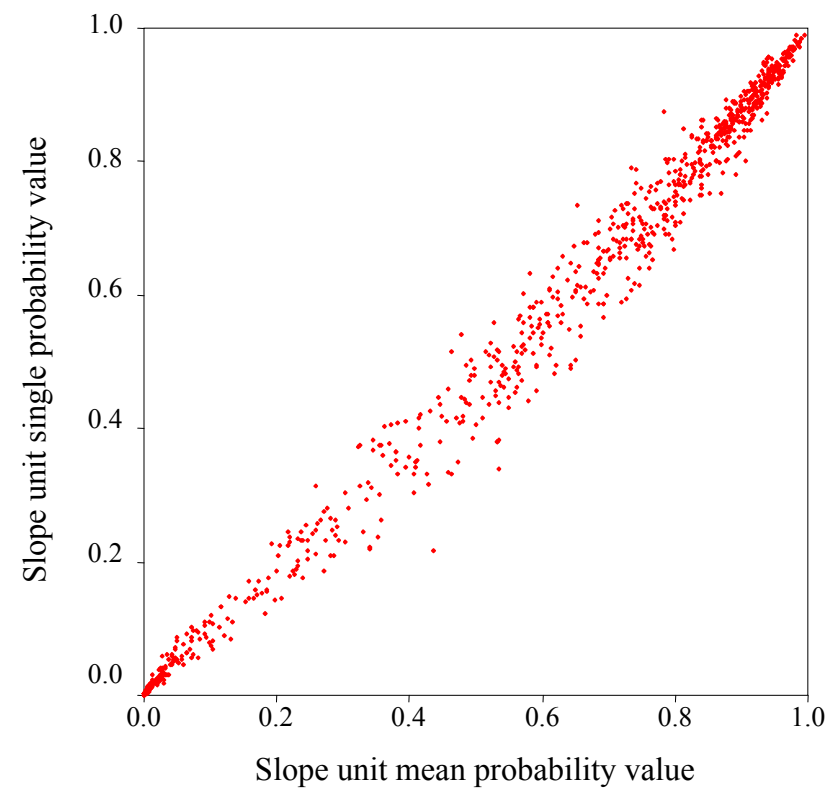

Fig. 7. Red dots show the relationship between the average value of 50 probability estimates obtained using randomly selected subsets of 760 mapping units (85\% of total number of map units) (xaxis), and the single probability value obtained for the susceptibility model shown in Fig. 5e (y-axis). Correlation coefficient, $\mathrm{r}^{2}=0.9876$. See text for explanation.

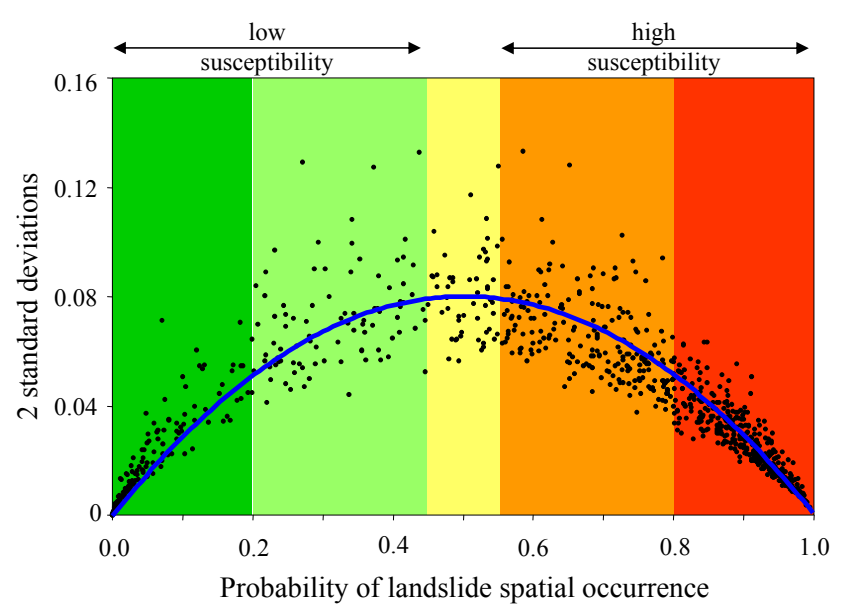

Fig. 8. Landslide susceptibility model error. The graph shows, for each of the 894 mapping units, the mean value of 50 probability estimates (x-axis) against two standard deviations $(2 \sigma)$ of the probability estimate (y-axis). Along $\mathrm{x}$-axis mapping units are ranked from low (left, green) to high (right, red) spatial probability of landslide occurrence. Colours indicate spatial probability in the same 5 classes shown in Fig. 5. Thick blue line shows estimated model error obtained by linear regression fit. Correlation coefficient, $r^{2}=0.8416$. See text for explanation.

We exploited the large number of susceptibility forecasts to estimate the error associated with the landslide susceptibility model shown in Fig. 5e. For each slope unit, Fig. 7 compares the mean value of the 50 probability estimates ( $\mathrm{x}$-axis) 


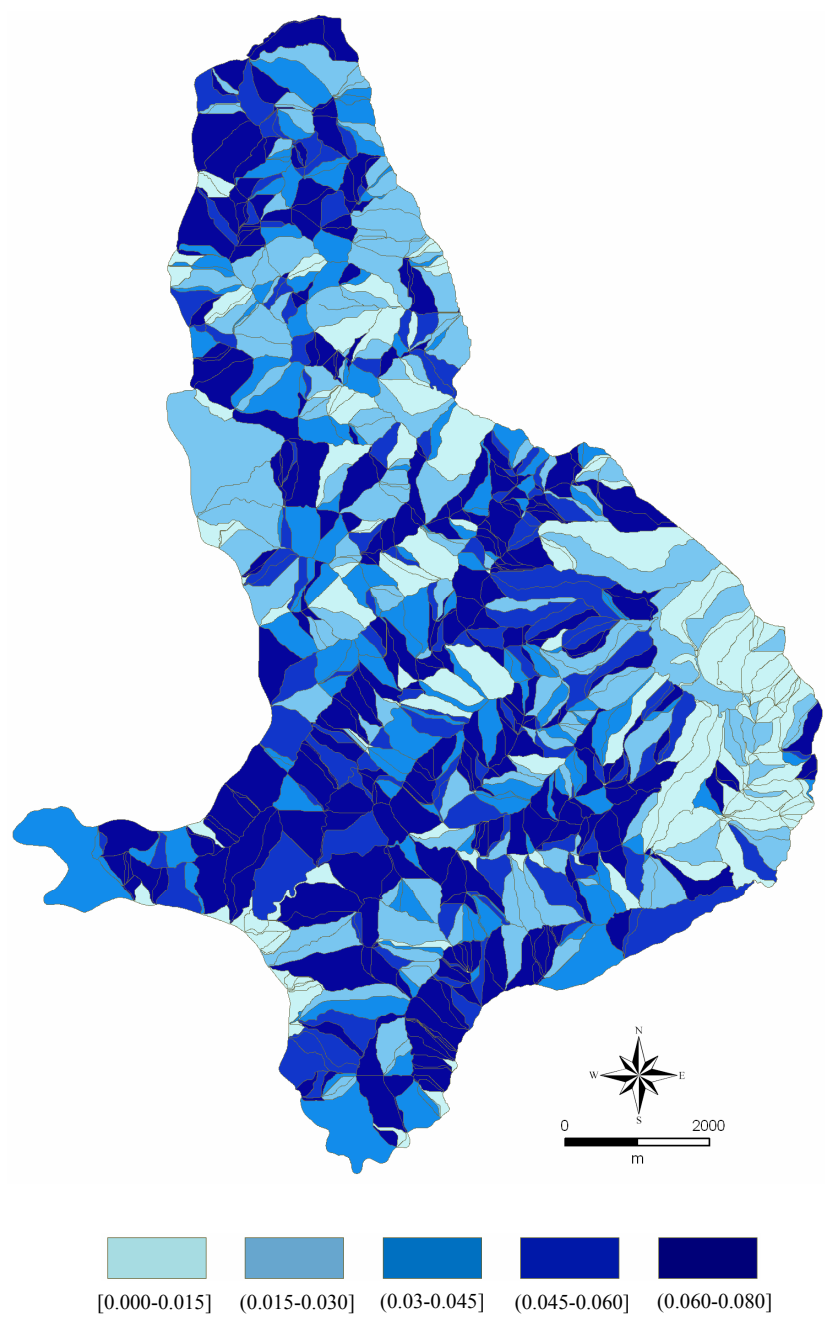

Fig. 9. Map showing estimated model error $(2 \sigma)$ for the susceptibility model shown in Fig. 5e. Model error computed using Eq. (3) is shown in 5 classes. Square bracket indicates class limit is included; round bracket indicates class limit is not included. See text for explanation.

with the single probability estimate obtained for the model shown in Fig. 5e (y-axis), which was prepared using the entire set of 894 slope units. The correlation between the two estimates of landslide susceptibility is very high $\left(r^{2}=0.9876\right)$. This is indication that the two classifications - despite some scatter - are very similar. Based on this result, we prepared Fig. 8 that shows, for the 894 slope units, the relationship between the ranking of landslide susceptibly (x-axis) and 2 standard deviations $(2 \sigma)$ of the probability estimate (y-axis). Inspection of Fig. 8 reveals that the measure of $2 \sigma$ is low $(<0.05)$ for slope units classified as highly susceptible (probability $>0.80$ ) and as largely stable (probability $<0.20$ ). The scatter in the probability estimate is larger for intermediate values of the probability (i.e., between 0.40 and 0.60 ). This indicates that for slope units having intermediate values of probability, not only is model $\mathrm{E}$ incapable of satisfactorily classifying the terrain as stable or unstable, but also that the

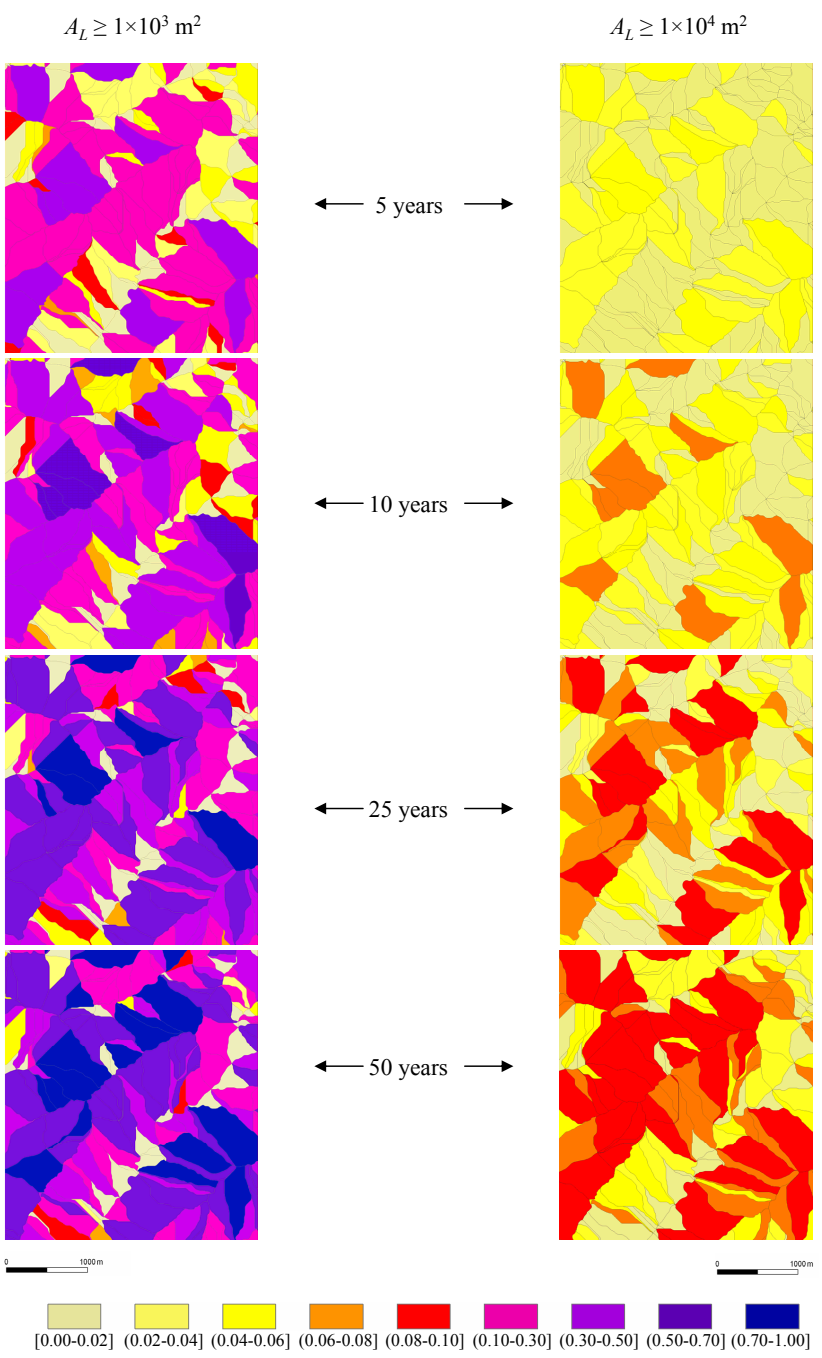

Fig. 10. Examples of landslide hazard maps for four periods, from 5 to 50 years (from top to bottom), and for two landslide sizes, $A_{L} \geq$ $1000 \mathrm{~m}^{2}$ (left) and $A_{L} \geq 10000 \mathrm{~m}^{2}$, i.e. 1 ha (right). Colours show different joint probabilities of landslide size, of landslide temporal occurrence, and of landslide spatial occurrence (susceptibility).

obtained estimate is highly variable and, most probably, unreliable. The variation in the probability estimate of landslide susceptibility can be approximated by the following equation, obtained by linear regression fit (least square method):

$y=-0.3218 x^{2}+0.3212 x \quad 0 \leq x \leq 1 \quad\left(r^{2}=0.8416\right)(3)$

where, $x$ is the estimated value of the probability of pertaining to an unstable slope unit, and $y$ is the corresponding $2 \sigma$ of the probability estimate.

We considered the value of $2 \sigma$ of the probability estimate a proxy for the model error, and we used Eq. (3) to estimate the model error for each slope unit, based on the computed probability estimate. For each slope unit, Fig. 9 shows the error associated with the probability estimate of landslide susceptibility computed using Eq. (3), and provides a quantitative measure of the error associated with the quantitative 


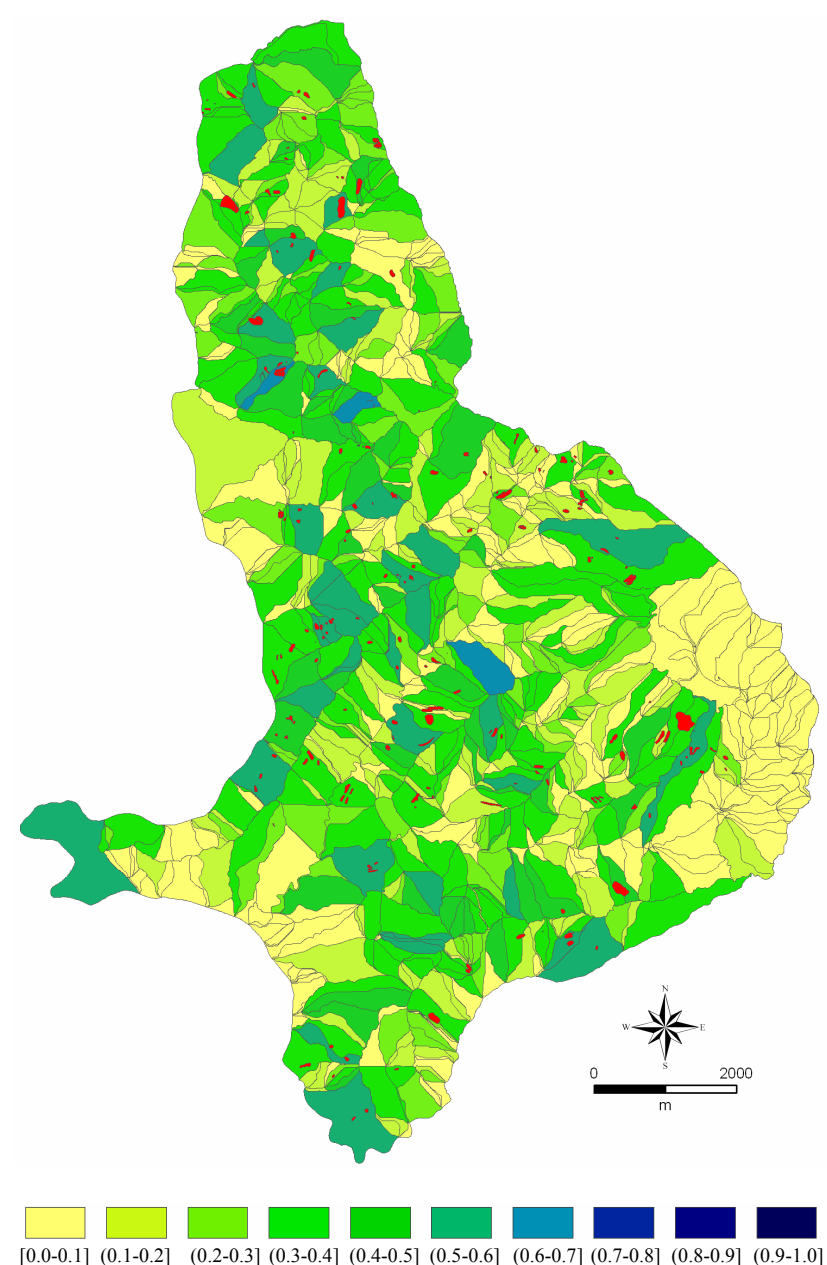

Fig. 11. Exceedance probability of landslide temporal occurrence in the 7-year period from 1998 to $2004\left(\mathrm{~F}_{1}-\mathrm{F}_{3}\right)$ based on the record of landslide occurrence in the period between 1941 and $1997\left(\mathrm{~A}_{2}-\right.$ $E_{2}$ ) obtained from the multi-temporal inventory. Square bracket indicates class limit is included; round bracket indicates class limit is not included.

landslide susceptibility assessment provided by model E, and shown in Fig. 5e.

\subsection{Landslide hazard}

We now have all the information required to determine quantitatively landslide hazard in the study area. We use:

(i) the probability of landslide size, a proxy for landslide magnitude, obtained from the statistical analysis of the frequency-area distribution of the mapped landslides (Fig. 3),

(ii) the probability of landslide occurrence for established periods, obtained by computing the mean recurrence interval between successive failures in each mapping unit, and adopting a Poisson probability model (Fig. 4, Table 4), and

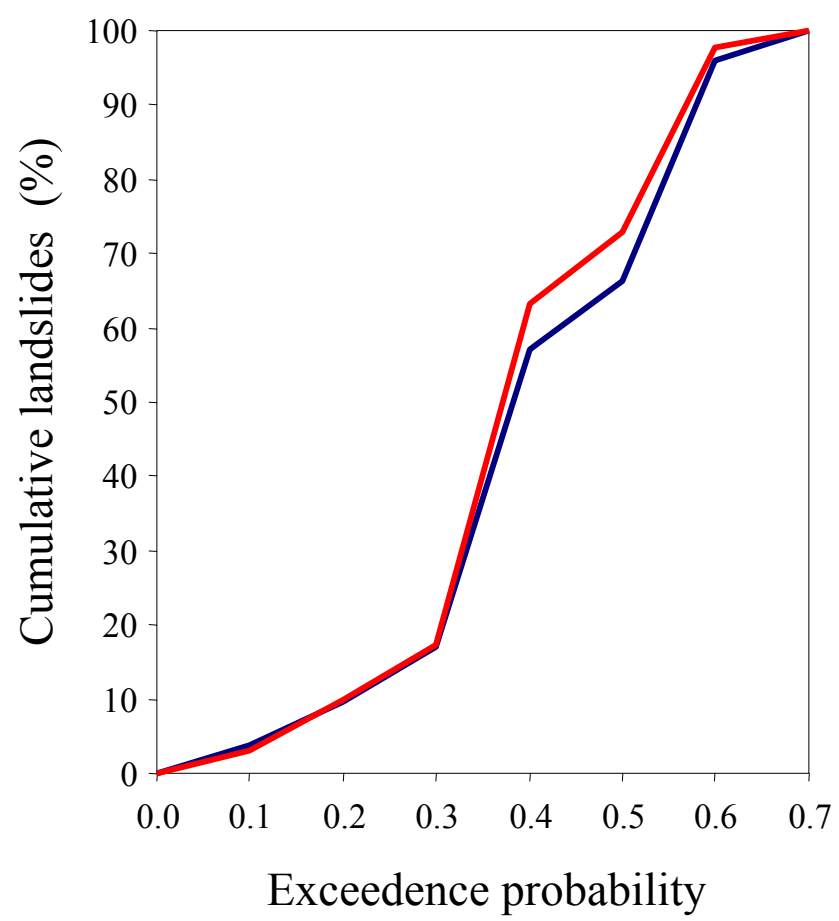

Fig. 12. Estimate of the prediction skill of the temporal forecast shown in Fig. 11. x-axis shows classes of the temporal probability obtained considering landslides in the period from 1941 to 1997 $\left(A_{2}-E_{2}\right)$. $y$-axis shows cumulative percentage of landslide area and landslide number in the period from 1998 to $2004\left(\mathrm{~F}_{1}-\mathrm{F}_{3}\right)$. Red line shows cumulative percentage of landslide area. Blue line shows cumulative percentage of landslide number.

(iii) the spatial probability of slope failures (i.e., susceptibility) obtained through discriminant analysis of 46 environmental variables (Fig. 5).

Assuming independence, we multiply the three probabilities and we obtain landslide hazard, i.e., the joint probability that a mapping unit will be affected by future landslides that exceed a given size, in a given time, and because of the local environmental setting. Figure 10 shows examples of the obtained landslide hazard assessment. This figure portrays landslide hazard for four periods (i.e., 5, 10, 25 and 50 years), and for two different landslide sizes, greater or equal than $1 \times 10^{3} \mathrm{~m}^{2}$, and greater or equal than $1 \times 10^{3} \mathrm{~m}^{4}(1 \mathrm{ha})$.

\section{Model validation}

The adopted probability model allows for its temporal and spatial verification. We first attempted a validation of the forecast of the temporal occurrence of landslides. For the purpose, we split the multi-temporal inventory covering the period from 1941 to $2004\left(\mathrm{~A}_{2}-\mathrm{F}_{3}\right)$ in to two sub-sets: (i) the 2250 landslides $(90.4 \%)$ in the period from 1941 to 1997 $\left(\mathrm{A}_{2}-\mathrm{E}_{2}\right)$, and (ii) the 240 landslides $(9.6 \%)$ occurred in the period from 1998 to $2004\left(\mathrm{~F}_{1}-\mathrm{F}_{3}\right)$. Using the first sub-set, we estimated the exceedance probability of landslide temporal 

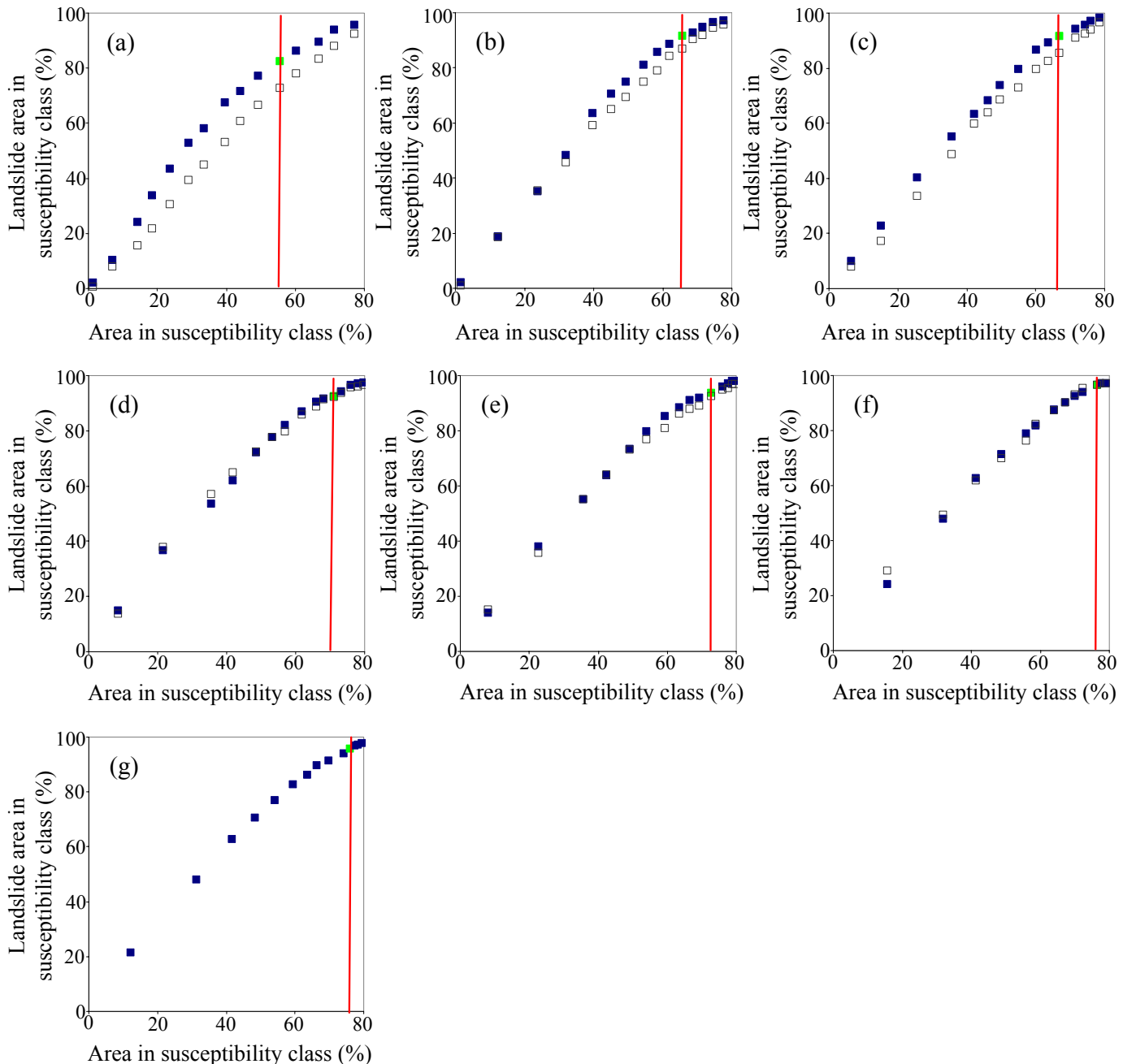

Fig. 13. Comparison of the susceptibility model fit and prediction performance. In the graphs, x-axes show the percentage of study area in each susceptibility class, ranked from most (left) to least (right) susceptible, and y-axes show the percentage of landslide area in each susceptibility class. Filled symbols measure the degree of model fit and open symbols measure the prediction skill of the susceptibility models. Red lines show 0.5 probability threshold, separating unstable $(P(S)<0.5)$ and stable $(P(S)>0.5)$ slope units.

occurrence in the 7-year period from 1998 to 2004 (Fig. 11). We then counted the number of landslides occurred in the period in each probability class. Results are shown in Fig. 12. In the 7-year considered period, the largest expected probability of landslide occurrence is 0.7 , indicating that nowhere in the study area landslides are expected to be "certain" in the period. Most of the mapped landslides ( 79\%) and most of the landslide areas $(\sim 81 \%)$ occurred in slope units with an expected probability of experiencing landslides ranging between 0.3 and 0.6. This is not a bad result, considering the difficulty of the task, and in particular considering: (i) the comparatively limited number of landslides occurred in the short validation period, (ii) the simplicity of the adopted Poisson model, and (iii) the temporal variability of landslide phenomena in the examined period.

Next, we attempted a validation of the spatial forecast of landslide occurrence, i.e., of landslide susceptibility. To accomplish this, we computed the total area of new landslides (at the date of the photographs) in each slope unit, and we compared the obtained values with the susceptibility zonings obtained by the seven different discriminant models (Fig. 5). Results are summarized in Fig. 13. In this figure, the graphs show on the $\mathrm{x}$-axis the percentage of the study area in each susceptibility class, ranked from most (left) to least (right) susceptible, and on the y-axis the percentage of landslide area in each susceptibility class. In each graph, the filled squares show the proportion of landslides used to construct the susceptibility model, and the open squares show the proportion of new landslides, i.e., the slope failures that occurred after the date of the landslides used to construct the models. Hence, the filled symbols measure the degree of model fit (i.e., the ability of a model to predict the location of the known landslides used to construct the model), whereas the open symbols measure the prediction skill of the susceptibility models (i.e., the ability of a model to predict the location of new landslides). The red lines show the 0.5 probability 
threshold, i.e., the limit between slope units classified as unstable $(P(S)<0.5)$ or stable $(P(S)>0.5)$ by the discriminant functions.

Inspection of Fig. 13 reveals that for models $\mathrm{A}, \mathrm{B}$ and $\mathrm{C}$, prepared using landslides $A_{1}, A_{1}-A_{2}$ and $A_{1}-B_{2}$, respectively, model fit (filled symbols) is significantly better than model prediction skill (open symbols). The difference between degree of model fit and model prediction skill decreases for the other models. We attribute the reduced difference to the increased number of landslides used to prepare the models, which corresponds to a larger proportion of the study area affected by slope failures. The percentage of territory classified as unstable by the seven susceptibility models increases from $55.6 \%$ (model $\mathrm{A}, \mathrm{A}_{1}$ ) to $76.6 \%$ (model $\mathrm{F}, \mathrm{A}_{1}-$ $\mathrm{E}_{2}$ ). Table 6 shows similar results. In this table, each block row corresponds to a susceptibility model and lists the percentage and the total landslide area mapped in a given period that falls in five classes of landslide susceptibility, from very high (VH) to very low (VL) susceptibility. The figures indicate how well a model was capable of predicting future landslides. All the models correctly classified as landslide prone more than $50 \%$ of the areas where "future" (with respect to the model) landslides occurred. As an example, model A (first block row in Table 6), which was prepared using only 270 landslides older than $1941\left(\mathrm{~A}_{1}\right)$, was capable of predicting $63.6 \%$ of all the landslides recognized as active in 1941 $\left(\mathrm{A}_{2}\right)$ and which occurred within high $(\mathrm{H}, 41.4 \%)$ and very high (VH, 22.2\%) susceptibility classes. Model A misclassified $23.5 \%$ of the landslide areas occurred in 1941 in slope units classified of low (L, 20.6\%) or very low (VL, 2.9\%) susceptibility. Model A performed less efficiently in predicting landslides occurred in the period from 1955 to 1977 $\left(\mathrm{C}_{1}-\mathrm{C}_{2}\right)$. For this period, the model was capable of correctly predicting $57.7 \%$ of the new landslides, and failed to predict $31.3 \%$ of the slope failures that occurred in low (24.4\%) and in very low (6.9\%) susceptibility areas. It is useful to check the ability of Model A to predict the location of the most recent landslides occurred in the Collazzone area, i.e., the landslides mapped in the period from 1998 to $2004\left(F_{1}-F_{3}\right)$. For this period, model A was capable of correctly predicting $58.1 \%$ of the new landslides, and failed to predict $30.6 \%$ of the slope failures that occurred in low $(25.0 \%)$ and in very low (5.6\%) susceptibility areas. Considering that model A was prepared using only 270 landslides, and considering the time elapsed from model "prediction" (1941) to model "verification" (2004), performance of the model should be considered satisfactory.

Data listed in Table 6 can also be used to determine the contribution of new landslides to the model prediction skills. Considering the last column, one can see that model A was capable of predicting $58.1 \%$ of the landslides occurred in the period from 1998 to $2004\left(\mathrm{~F}_{1}-\mathrm{F}_{3}\right)$, whereas model $\mathrm{E}$ correctly predicted $89.7 \%$ of the landslides in the same period, with the majority of the slope failures $(61.4 \%)$ falling in the very high susceptibility class and only $2.0 \%$ of the landslides occurring in the very low susceptibility class.

\section{Discussion}

The adopted landslide hazard model holds under a set of assumptions (Guzzetti et al., 2005), namely that: (i) landslides will occur in the future under the same circumstances and because of the same factors that produced them in the past, (ii) landslide events are independent (uncorrelated) random events in time, (iii) the mean recurrence of slope failures will remain the same in the future as it was observed in the past, (iv) the statistics of landslide area do not change in time, (v) landslide area is a reasonable proxy for landslide magnitude, and (vi) the probability of landslide size, the probability of landslide occurrence for established periods, and the spatial probability of slope failures, are all independent. We now discuss the validity of these assumptions for the Collazzone study area. We anticipate that the results are not significantly different from the results obtained previously in the northern Italian Apennines (Guzzetti et al., 2005).

That landslides will occur in the future under the same conditions and because of the same factors that triggered them in the past - a consequence of the principle of uniformitarianism - is a recognized postulate for all functional susceptibility or hazard assessments (Carrara et al., 1991; Hutchinson, 1995; Aleotti and Chowdhury, 1999; Chung and Fabbri, 1999; Guzzetti et al., 1999). This assumption has geomorphological limitations (Guzzetti et al., 2005). First-time failures occur under conditions of peak resistance (friction and cohesion), whereas landslide reactivations occur under intermediate or residual conditions. Slope failures change the morphology of the terrain where the failures occur, and when a landslide moves, it may change the hydrological conditions of the slope. Further, landslides can change their type of movement and velocity with time. Lastly, landslide occurrence and abundance are a function of environmental conditions that vary with time at different rates. Some of these environmental variables are affected by human actions (e.g., land use, deforestation, irrigation, etc.), which are also highly changeable. Because of these complications, each landslide occurs in a distinct local environmental context. Despite the inherent limitations, in this work we have assumed that in the study area future landslides will occur on average under the same circumstances and because of the same conditions that triggered them in the past. We further assumed that our knowledge of the distribution of past failures was reasonably accurate and complete.

The difficulty with the adopted assumption lays in the fact that the environmental conditions (predisposing factors) that caused landslides must remain the same in the future in order to cause similar slope failures. We can assume that our hazard model has an expected validity of 50 years. The problem is to investigate the possibility that the predisposing factors will change in the 50-year period. In the study area, it is safe to assume that geological factors (e.g., lithology, structure, seismicity) will not change significantly in such a short geological time. Local morphological modifications are certainly possible, due chiefly to stream erosion, landslides and human actions, but extensive (widespread) morphological 
Table 6. Validation of landslide susceptibility models prepared for the Collazzone area. Susceptibility classes are: VH, very high [1.0-0.8); $\mathrm{H}$, high [0.8-0.6); U, uncertain [0.6-0.4); L, low [0.4-0.2); and VL, very low [0.0-0.2]. Square bracket indicates class limit is included; round bracket indicates class limit is not included. See text for explanation.

\begin{tabular}{|c|c|c|c|c|c|c|c|c|c|c|c|c|c|}
\hline & \multicolumn{13}{|c|}{ Landslides } \\
\hline & $\begin{array}{l}\text { Susceptibility } \\
\text { class }\end{array}$ & $\begin{array}{l}\mathrm{A}_{2} \\
\mathrm{~m}^{2}\end{array}$ & $\%$ & $\begin{array}{r}\mathrm{B}_{1}-\mathrm{B}_{2} \\
\mathrm{~m}^{2}\end{array}$ & $\%$ & $\begin{array}{r}\mathrm{C}_{1}-\mathrm{C}_{2} \\
\mathrm{~m}^{2}\end{array}$ & $\%$ & $\begin{array}{r}\mathrm{D}_{1}-\mathrm{D}_{2} \\
\mathrm{~m}^{2}\end{array}$ & $\%$ & $\begin{array}{r}E_{1}-E_{2} \\
m^{2}\end{array}$ & $\%$ & $\begin{array}{r}\mathrm{F}_{1}-\mathrm{F}_{3} \\
\mathrm{~m}^{2}\end{array}$ & $\%$ \\
\hline \multirow{5}{*}{$\begin{array}{l}\text { Model A } \\
\left(\mathrm{A}_{1}\right)\end{array}$} & VH & 911140.6 & 22.2 & 270108.7 & 23.9 & 454661.6 & 21.1 & 198483.3 & 18.7 & 180541.5 & 17.4 & 158462.5 & 23.1 \\
\hline & $\mathrm{H}$ & 1697192.4 & 41.4 & 403642.4 & 35.8 & 787829.8 & 36.6 & 459594.8 & 43.4 & 458563.8 & 44.2 & 240365.7 & 35.0 \\
\hline & $\mathrm{U}$ & 528725.9 & 12.9 & 127781.7 & 11.3 & 234966.3 & 10.9 & 116624.4 & 11.0 & 97879.6 & 9.4 & 78145.6 & 11.4 \\
\hline & $\mathrm{L}$ & 843823.1 & 20.6 & 261978.1 & 23.2 & 525874.0 & 24.4 & 241526.1 & 22.8 & 213053.2 & 20.5 & 171694.4 & 25.0 \\
\hline & VL & 117690.9 & 2.9 & 65517.8 & 5.8 & 147766.3 & 6.9 & 42881.7 & 4.0 & 87558.2 & 8.4 & 38142.0 & 5.6 \\
\hline \multirow{5}{*}{$\begin{array}{l}\text { Model B } \\
\left(\mathrm{A}_{1}-\mathrm{A}_{2}\right)\end{array}$} & VH & & & 541984.9 & 48.0 & 992951.9 & 46.2 & 542926.3 & 51.3 & 480519.6 & 46.3 & 308755.7 & 45.0 \\
\hline & $\mathrm{H}$ & & & 371180.2 & 32.9 & 685888.0 & 31.9 & 363631.1 & 34.3 & 379343.5 & 36.6 & 189673.3 & 27.6 \\
\hline & $\mathrm{U}$ & & & 101845.1 & 9.0 & 159079.9 & 7.4 & 44413.2 & 4.2 & 67523.6 & 6.5 & 80850.9 & 11.8 \\
\hline & $\mathrm{L}$ & & & 86376.4 & 7.7 & 263763.8 & 12.3 & 88732.4 & 8.4 & 61269.9 & 5.9 & 84186.9 & 12.3 \\
\hline & VL & & & 27642.0 & 2.4 & 49414.4 & 2.3 & 19407.4 & 1.8 & 48939.8 & 4.7 & 23343.3 & 3.4 \\
\hline \multirow{5}{*}{$\begin{array}{l}\text { Model C } \\
\left(\mathrm{A}_{1}-\mathrm{B}_{2}\right)\end{array}$} & VH & & & & & 1016348.7 & 47.2 & 535420.5 & 50.6 & 562019.0 & 54.2 & 309502.5 & 45.1 \\
\hline & $\mathrm{H}$ & & & & & 707578.8 & 32.9 & 325653.6 & 30.7 & 318229.8 & 30.7 & 230271.7 & 33.5 \\
\hline & $\mathrm{U}$ & & & & & 106075.3 & 4.9 & 99624.3 & 9.4 & 40110.7 & 3.9 & 40036.0 & 5.8 \\
\hline & $\mathrm{L}$ & & & & & 275302.8 & 12.8 & 90518.6 & 8.5 & 73078.6 & 7.0 & 86976.5 & 12.7 \\
\hline & VL & & & & & 45792.3 & 2.1 & 7893.5 & 0.7 & 44158.2 & 4.3 & 20023.4 & 2.9 \\
\hline \multirow{5}{*}{$\begin{array}{l}\text { Model D } \\
\left(\mathrm{A}_{1}-\mathrm{C}_{2}\right)\end{array}$} & VH & & & & & & & 716215.8 & 67.6 & 733293.9 & 70.7 & 413097.3 & 60.1 \\
\hline & $\mathrm{H}$ & & & & & & & 252034.5 & 23.8 & 191491.7 & 18.5 & 199123.4 & 29.0 \\
\hline & U & & & & & & & 21060.9 & 2.0 & 17116.3 & 1.6 & 20407.3 & 3.0 \\
\hline & $\mathrm{L}$ & & & & & & & 49859.5 & 4.7 & 52290.9 & 5.0 & 34293.2 & 5.0 \\
\hline & VL & & & & & & & 19939.8 & 1.9 & 43403.6 & 4.2 & 19888.8 & 2.9 \\
\hline \multirow{5}{*}{$\begin{array}{l}\text { Model E } \\
\left(\mathrm{A}_{1}-\mathrm{D}_{2}\right)\end{array}$} & VH & & & & & & & & & 697304.1 & 67.2 & 421936.4 & 61.4 \\
\hline & $\mathrm{H}$ & & & & & & & & & 232577.8 & 22.4 & 194225.1 & 28.3 \\
\hline & U & & & & & & & & & 19079.0 & 1.8 & 31693.8 & 4.6 \\
\hline & $\mathrm{L}$ & & & & & & & & & 50110.9 & 4.8 & 25008.2 & 3.6 \\
\hline & VL & & & & & & & & & 38524.5 & 3.7 & 13946.5 & 2.0 \\
\hline \multirow{5}{*}{$\begin{array}{l}\text { Model F } \\
\left(\mathrm{A}_{1}-\mathrm{E}_{2}\right)\end{array}$} & VH & & & & & & & & & & & 478955.5 & 69.7 \\
\hline & $\mathrm{H}$ & & & & & & & & & & & 159285.7 & 23.2 \\
\hline & $\mathrm{U}$ & & & & & & & & & & & 24279.4 & 3.5 \\
\hline & $\mathrm{L}$ & & & & & & & & & & & 10343.0 & 1.5 \\
\hline & VL & & & & & & & & & & & 13946.5 & 2.0 \\
\hline
\end{tabular}

changes are not expected. Inspection of Table 5 indicates that 29 of the 32 thematic variables entered into the susceptibility models are not expected to change significantly in the considered period. However, land use types (three variables, BOSCO, SA, FRUTT) may change significantly in the period. In a representative portion of the Collazzone area, comparison of land-use maps obtained form aerial photographs taken in 1941 (B in Table 1) and aerial photographs taken in 1999 , revealed a reduction of about $65 \%$ of the forest coverage in the 57-year period, in favour chiefly of cultivated land. In the same period, agricultural practices have changed significantly, largely aided by new mechanical equipments. In the central Apennines, areas recently deforested for agricultural purposes are generally more prone to shallow landslides. If this will be the case for the Collazzone area, some of the environmental variables considered in the susceptibility model will change, possibly hampering the validity of the model, and new variables describing land use change should be considered to forecast the location of new slope failures.
The available susceptibility model (Fig. 5e, Table 5) does not consider the landslide triggering factors, i.e., rainfall, seismic shaking or snow melting. Changes in the frequency or intensity of the driving forces will not affect (at least not in the considered period) the susceptibility model. However, they may affect the rate of occurrence of landslide events.

In the Apennines, evidence exists that where abundant clay, marl and sandstone crop out, landslides exhibit spatial persistence, i.e., slope failures tend to occur where they have occurred in the past. Guzzetti et al. (2005) tested this hypothesis in the Staffora River basin in the northern Apennines and found that for a period of 50 years landslide events could be considered uncorrelated events in time and these could be modelled designing a Poisson-type model. Following the same approach, we note that in the Collazzone study area $33 \%$ of the total number of landslides identified in the period from 1941 to $2004\left(\mathrm{~A}_{2}-\mathrm{F}_{3}\right)$ occurred inside landslides classified as older than $1941\left(\mathrm{~A}_{0}-\mathrm{A}_{1}\right)$. 
Analysis of the historical record of damaging landslide events in Umbria indicates that in the 85-year period from 1917 to 2001, 1497 landslide events occurred at 1286 different sites, with only 75 sites affected two or more times, and only one site affected four times. Based on this historical record, the same landslide site was affected on average 1.16 times, indicating a low rate of recurrence of landslide events at the same site. Despite known incompleteness of the historical record (Guzzetti et al., 2003; Guzzetti and Tonelli, 2004), the obtained findings concur to determine that for the period of our hazard assessment (50 years), in the Collazzone area landslides can be considered uncorrelated random events in time.

Further analysis of the historical record of landslide events in Umbria reveals that of the 889 events for which the triggering mechanism is known, the majority $(720,80.9 \%)$ were the result of intense rainfall. The remaining landslide events were due to rapid snow melting $(37,4.2 \%)$, infiltration (135, $15.2 \%)$, earthquake shaking $(38,4.3 \%)$, erosion of the toe of the slope $(59,6.6 \%)$, human actions on artificial slopes $(81,9.1 \%)$, and other causes $(39,4.3 \%)$. The statistics indicates that meteorological triggers (rainfall and snow melting) cause most of the landslides in Umbria (and in the Collazzone area). If the rate of occurrence of the meteorological events that trigger landslides changes, the mean rate of slope failures will also change. If the intensity (amplitude and duration) of the rainfall will change, the rate of slope failures might change, in a way that is not easily predictable. Modifications in land use induced by changes in agricultural practices may also change the rate of occurrence of landslides.

Determining the statistics of landslide areas is no trivial task (Malamud et al., 2004). The (scant) available information indicates that the frequency-area statistics of landslide areas does not change significantly across lithological or physiographical boundaries. Malamud et al. (2004) showed that three different populations of landslides produced by different triggers (i.e., seismic shaking, intense rainfall, rapid snow melting) in different physiographical regions (southern California, central America, central Italy), exhibit virtually identical probability density functions. Unpublished work conducted in central Italy indicates that for the same physiographical region the probability density of landslide area does not change significantly in time. It is therefore safe to assume that in the Collazzone area the frequency-area statistics of landslide area will not change in the 50-year period of the hazard assessment. Since the most abundant landslides in the study area are small $\left(\sim 1 \times 10^{3} \mathrm{~m}^{2}\right.$, Fig. 3a), great care must be taken in mapping accurately the small slope failures. The slope of the heavy tail of the probability density distribution shown in Fig. 3a is controlled by a limited number of landslides. There are 23 landslides $(0.82 \%)$ larger than $1 \times 10^{5} \mathrm{~m}^{2}$ and only one landslide $(0.03 \%)$ larger than one square kilometre. Care must be taken in mapping the largest landslides, and in deciding whether they represent an individual slope failure or the result of two or more coalescent landslides.
No unique measure of landslide magnitude is available. Hungr (1997) proposed to use destructiveness as a measure of landslide magnitude. In this work, we have adopted landslide area as a proxy for landslide destructiveness and of landslide magnitude. We obtained the area of the individual slope failures from the multi-temporal landslide inventory. To determine if landslide area is a reasonable measure of landslide destructiveness in the Collazzone area we have analysed the historical catalogue of damaging slope failures in Umbria. Information on the size (area, length, width) of landslides is available for 344 events $(22.9 \%)$, which range from $1.0 \times 10^{3} \mathrm{~m}^{2}$ to more than one square kilometre (mean $=1.64 \times 10^{4} \mathrm{~m}^{2}$ ). Damage caused by these landslides was mostly to the road network (73 events) and, subordinately, to private homes (53 events) and to the infrastructure (30 events). Twenty-two landslide events produced casualties, and 12 landslides produced 22 fatalities, none of which in the Collazzone area. Information on the landslide type is available for 368 events (24.6\%), of which 152 were slides, 31 flows and 148 falls. Slides and flows caused the most severe damage, and falls produced minor interruptions along the roads. As a whole, the available historical information on damaging slope failures in Umbria concurs to establish that: (i) damage in the Collazzone area is expected mostly from slow to rapid moving slides and flows, i.e., the type of failures considered in the hazard assessment, and (ii) large landslides are expected to produce a larger damage, particularly to roads and private buildings in old villages and single dwellings.

The last assumption of the adopted hazard model is that the probabilities of landslide size $P\left(A_{L}\right)$, of temporal occurrence $P\left(N_{L}\right)$, and of spatial incidence of mass movements $P(S)$ are independent. The legitimacy of this assumption is difficult to prove. We have shown that the probability of landslide area is largely independent from the physiographical setting. As a first-approximation, it is safe to conclude that the probability of landslide area is independent from susceptibility. The susceptibility model was constructed without considering the driving forces (meteorological or else) that control the rate of occurrence of slope failures in the study area. We conclude that the rate of landslide events is independent from susceptibility. The catalogue of historical damaging landslides reveals that landslides occurred in all sizes. We consider this an indication that the rate of failures is independent from landslide size.

\section{Concluding remarks}

To ascertain landslide hazard in the Collazzone area we have adopted the probabilistic model proposed by Guzzetti et al. (2005). The adopted model expresses landslide hazard as the joint probability of landslide size, considered a proxy for landslide magnitude, of landslide occurrence in an established period, and of landslide spatial occurrence, given the local environmental setting. For the study area we have obtained most of the information used to determine landslide 
hazard from a detailed multi-temporal inventory map, prepared through the interpretation of five sets of aerial photographs and field surveys. The adopted model proved applicable in the test area. We judge the model appropriate in similar areas, and chiefly where a multi-temporal landslide inventory captures the types, sizes, and expected recurrence of slope failures. We tested the model ability to predict the location of new or reactivated landslides, and the predicted temporal occurrence of the slope failures. We found the former better than the latter, confirming the difficulty in predicting when or how frequently slope failures will occur in an area.

We conclude by pointing out that the main scope of a landslide hazard assessment is to provide probabilistic expertise on future slope failures to planners, decision makers, civil defence authorities, insurance companies, land developers, and individual landowners. The adopted method allowed us to prepare a large number of different hazard maps (Fig. 10), depending on the adopted susceptibility model, the established period, and the minimum size of the expected landslide. How to combine such a large number of hazard scenarios efficiently, producing cartographic, digital, or thematic products useful for the large range of interested users, remains an open problem that needs further investigation.

Acknowledgements. Work supported by CNR IRPI and Riskaware (Interreg III-C CADSES Programme) grants. CNR GNDCI publication number 2905.

Edited by: L. Ferraris

Reviewed by: N. Casagli and another referee

\section{References}

Aleotti, P. and Chowdhury, R.: Landslide hazard assessment: summary review and new perspectives, Bull. Engi. Geology and the Environ., 58, 21-44, 1999.

Barchi, M., Brozzetti, F., and Lavecchia, G.: Analisi strutturale e geometrica dei bacini della media valle del Tevere e della valle umbra, (in Italian), Bollettino Società Geologica Italiana, 110, 65-76, 1991.

Canuti, P. and Casagli, N.: Considerazioni sulla valutazione del rischio di frana. CNR - GNDCI Pubblication number 846, Proceedings conference Fenomeni franosi e centri abitati, Bologna, 27 May 1994, CNR - GNDCI and Regione Emilia-Romagna, (in Italian), 29-130, 1994.

Cardinali, M., Ardizzone, F., Galli, M., Guzzetti, F., and Reichenbach, P.: Landslides triggered by rapid snow melting: the December 1996-January 1997 event in Central Italy, Proceedings 1st Plinius Conference on Mediterranean Storms, edited by: Claps, P. and Siccardi, F., Bios Publisher, Cosenza, 439-448, 2002a.

Cardinali, M., Reichenbach, P., Guzzetti, F., Ardizzone, F., Antonini, G., Galli, M., Cacciano, M., Castellani, M., and Salvati, P.: A geomorphological approach to estimate landslide hazard and risk in urban and rural areas in Umbria, central Italy, Nat. Hazards Earth Syst. Sci., 2, 57-72, 2002b,

SRef-ID: 1684-9981/nhess/2002-2-57.
Carrara, A.: A multivariate model for landslide hazard evaluation, Mathematical Geology, 15, 403-426, 1983.

Carrara, A., Cardinali, M., Detti, R., Guzzetti, F., Pasqui, V., and Reichenbach, P.: GIS Techniques and statistical models in evaluating landslide hazard, Earth Surface Processes and Landform, 16, 5, 427-445, 1991.

Carrara, A., Cardinali, M., Guzzetti, F., and Reichenbach, P.: GIS technology in mapping landslide hazard, in: Geographical Information Systems in Assessing Natural Hazards, edited by: Carrara, A. and Guzzetti, F., Kluwer Academic Publisher, Dordrecht, The Netherlands, 135-175, 1995.

Chung, C. J. and Frabbri, A. G.: Probabilistic prediction models for landslide hazard mapping, Photogrammetric Engineering \& Remote Sensing, 65, 12, 1389-1399, 1999.

Cencetti, C.: Il Villafranchiano della "riva umbra" del F. Tevere: elementi di geomorfologia e di neotettonica. Bollettino Società Geologica Italiana, (in Italian), 109, 2, 337-350, 1990.

Coe, J. A., Michael, J. A., Crovelli, R. A., and Savage, W. Z.: Preliminary map showing landslide densities, mean recurrence intervals, and exceedance probabilities as determined from historic records, Seattle, Washington, United States Geological Survey Open File Report 00-303, 2000.

Conti, M. A. and Girotti, O.: Il Villafranchiano nel "Lago Tiberino", ramo sud-occidentale: schema stratigrafico e tettonico, Geologica Romana, (in Italian), 16, 67-80, 1977.

Crovelli, R. A.: Probability models for estimation of number and costs of landslides, United States Geological Survey Open File Report 00-249, 2000.

Cruden, D. M. and Varnes, D. J.: Landslide types and processes, in: Landslides, Investigation and Mitigation, edited by: Turner, A. K. and Schuster, R. L., Transportation Research Board Special Report 247, Washington D.C., 36-75, 1996.

Einstein, H. H.: Special lecture: Landslide risk assessment procedure, in: Landslides, edited by: Bonnard, C., 2, 1075-1090, 1988.

Guzzetti, F. and Cardinali, M.: Carta Inventario dei Fenomeni Franosi della Regione dell'Umbria ed aree limitrofe, CNR Gruppo Nazionale per la Difesa dalle Catastrofi Idrogeologiche Publication n. 204, 2 sheets, scale 1:100 000, (in Italian), 1989.

Guzzetti, F. and Cardinali, M.: Landslide inventory map of the Umbria region, Central Italy, in: Proceedings ALPS 90 6th International Conference and Field Workshop on Landslides, edited by: Cancelli, A., Milan, 12 September 1990, 273-284, 1990.

Guzzetti, F., Carrara, A., Cardinali, M., and Reichenbach, P.: Landslide hazard evaluation: a review of current techniques and their application in a multi-scale study, Central Italy, Geomorphology, 31, 181-216, 1999.

Guzzetti, F., Malamud, B. D., Turcotte, D. L., and Reichenbach, P.: Power-law correlations of landslide areas in Central Italy, Earth and Planetary Science Letters, 195, 169-183, 2002.

Guzzetti, F., Reichenbach, P., Cardinali, M., Ardizzone, F., and Galli, M.: Impact of landslides in the Umbria Region, Central Italy, Nat. Hazards Earth Syst. Sci., 3, 469-486, 2003,

SRef-ID: 1684-9981/nhess/2003-3-469.

Guzzetti, F., Reichenbach, P., Ardizzone F., Cardinali, M., and Galli, M.: Probabilistic landslide hazard assessment at the basin scale, Geomorphology, 72, 272-299, 2005.

Guzzetti, F. and Tonelli, G.: SICI: an information system on historical landslides and floods in Italy, Nat. Hazards Earth Syst. Sci., 4, 213-232, 2004,

SRef-ID: 1684-9981/nhess/2004-4-213. 
Hungr, O.: Some methods of landslide hazard intensity mapping, in: Landslide risk assessment, edited by: Cruden, D. M. and Fell, R., Balkema Publisher, Rotterdam, 215-226, 1997.

Hutchinson, J. N.: Keynote paper: Landslide hazard assessment, in: Landslides, Balkema, Rotterdam, edited by: Bell, D. H., 18051841, 1995.

Keaton, J. R., Anderson, L. R., and Mathewson, C. C.: Assessing debris flow hazards on alluvial fans in Davis County, Utah, in: Proceedings 24th Annual Symposium on Engineering Geology and Soil Engineering, edited by: Fragaszy, R. J., Pullman, Washington State University, 89-108, 1988.

Lips, E. W. and Wieczorek, G. F.: Recurrence of debris flows on an alluvial fan in central Utah, in: Hydraulic/Hydrology of Arid Lands, edited by: French, R. H., Proceedings of the International Symposium, American Society of Civil Engineers, 555560, 1990.

Malamud, B. D., Turcotte, D. L., Guzzetti, F., and Reichenbach, P.: Landslide inventories and their statistical properties, Earth Surface Processes and Landforms, 29, 6, 687-711, 2004.

McCalpin, J.: Preliminary age classification of landslides for inventory mapping: 21st Annual Symposium on Engineering Geology and Soils Engineering, 5-6 April 1984, Pocatello, Idaho, 13 p., 1984.

Reichenbach, P., Galli, M., Cardinali, M., Guzzetti, F., and Ardizzone, F.: Geomorphologic mapping to assess landslide risk: concepts, methods and applications in the Umbria Region of central Italy, in: Landslide risk assessment, edited by: Glade, T., Anderson, M., and Crozier, M. J., John Wiley, 429-468, 2005.
Servizio Geologico Nazionale: Carta Geologica dell'Umbria. Map at 1:250 000 scale, (in Italian), 1980.

Soeters, R. and van Westen, C. J.: Slope instability recognition analysis and zonation, in: Landslide investigation and mitigation, edited by: Turner, A. K. and Schuster, R. L., National Research Council, Transportation Research Board Special Report 247, Washington, 129-177, 1996.

Stark, C. P. and Hovius, N.: The characterization of landslide size distributions, Geophys. Res. Lett., 28, 6, 1091-1094, 2001.

van Westen, C. J.: GIS in landslide hazard zonation: A review with examples from the Colombian Andes, in: Taylor and Francis, edited by: Price, M. F. and Heywood, D. I., London, 135-165, 1994.

Varnes, D. J. and IAEG Commission on Landslides and other MassMovements: Landslide hazard zonation: a review of principles and practice, UNESCO Press, Paris, 63 p., 1984.

WP/WLI - International Geotechnical societies' UNESCO Working Party on World Landslide Inventory: A suggested method for reporting a landslide, International Association Engineering Geology Bulletin, 41, 5-12, 1990. 